\title{
Low Temperature Plasma: A Novel Focal Therapy for Localized Prostate Cancer?
}

\author{
Adam M. Hirst, ${ }^{1}$ Fiona M. Frame, ${ }^{2}$ Norman J. Maitland, ${ }^{2}$ and Deborah O'Connell ${ }^{1}$ \\ ${ }^{1}$ Department of Physics, York Plasma Institute, University of York, Heslington, York YO10 5DD, UK \\ ${ }^{2}$ YCR Cancer Research Unit, Department of Biology, University of York, Heslington, York YO10 5DD, UK
}

Correspondence should be addressed to Norman J. Maitland; njm9@york.ac.uk

Received 16 December 2013; Accepted 6 February 2014; Published 13 March 2014

Academic Editor: Giovanni Luca Gravina

Copyright (C) 2014 Adam M. Hirst et al. This is an open access article distributed under the Creative Commons Attribution License, which permits unrestricted use, distribution, and reproduction in any medium, provided the original work is properly cited.

Despite considerable advances in recent years for the focal treatment of localized prostate cancer, high recurrence rates and detrimental side effects are still a cause for concern. In this review, we compare current focal therapies to a potentially novel approach for the treatment of early onset prostate cancer: low temperature plasma. The rapidly evolving plasma technology has the potential to deliver a wide range of promising medical applications via the delivery of plasma-induced reactive oxygen and nitrogen species. Studies assessing the effect of low temperature plasma on cell lines and xenografts have demonstrated DNA damage leading to apoptosis and reduction in cell viability. However, there have been no studies on prostate cancer, which is an obvious candidate for this novel therapy. We present here the potential of low temperature plasma as a focal therapy for prostate cancer.

\section{Introduction}

Prostate cancer is now recognised as the second most diagnosed cancer overall and accounts for around a quarter of all cancers in males [1]. The risk of prostate cancer peaks in men over 60 years of age, yet high incidence rates are also found in younger aged groups [2]. In addition, benign enlargement of the prostate becomes increasingly common in men over the age of 40 and particularly so beyond 60 years of age [3].

Treatment for advanced prostate cancer is still unsatisfactory, with an almost inevitable development of hormone resistance [4]. Even new generation androgen ablation drugs fail to deliver a life extension beyond several months [5]. In addition, there is poor response to chemotherapy, alongside unpleasant side effects, and reduced quality of life [6]. Therefore, the emphasis remains to detect and treat prostate cancer at an early stage to have most hope of a cure. Indeed, early diagnosis has become more common with increased uptake of PSA testing $[7,8]$.

Once prostate cancer is diagnosed, the clinician is presented with a series of dilemmas; firstly, is the tumour localized or has it spread [9]; second, if localized is it potentially aggressive or indolent [10]; and the third, should the patient undergo active surveillance or be treated immediately
[11]. If the latter is chosen in the context of a localized tumour, then the next decision is between radical surgery with the risk of incontinence and impotence, radiotherapy, or treatment with a focal therapy [12]. Radical surgery has the potential to be an overtreatment in early-onset or lowrisk disease [13], where active surveillance or treatment with a focal therapy may be more suitable [14]. Ideally, focal therapy is targeted to maximize elimination of the tumour foci without treating the whole gland, while minimizing side effects $[15,16]$. This review aims to evaluate several currently available focal therapies for prostate cancer and introduces a potential focal treatment in the form of low temperature plasma (LTP). Application of LTPs to internal organs such as the prostate may seem technically difficult but could offer many advantages over current treatments.

\section{Approaches to Focal Therapy of Localized Prostate Cancer}

For patients to be considered as candidates for focal therapy, their prostate cancer must be present in only one lobe, typically unifocal, and contained within the prostate capsule [17]. However, no absolute ideal patient selection criteria exist 
for focal prostate treatment [18]. In the following subsections, some focal therapies for localized prostate cancer are briefly analyzed, with their respective advantages and pitfalls outlined for comparison. In addition, the importance of imaging techniques in the context of focal therapy treatments is also discussed.

2.1. High-Intensity Focused Ultrasound. The concept of highintensity focused ultrasound (HIFU) was first applied in the 1980s to benign prostate hyperplasia (BPH) [19], with the first recorded application to localized prostate cancer in 1995 [20]. The physical mechanism of HIFU follows the same principles as diagnostic ultrasound, whereby ultrasonic waves pass through healthy tissues without causing harm. However, if the ultrasonic beam is sufficiently focused and the intensity increased, high levels of energy can be delivered to very localized regions [7]. These high levels of energy are capable of causing irreversible damage to the targeted tissue via hyperthermia mechanisms, either by heating or inertial cavitation [7, 21, 22]. In the case of thermal effects, energy delivered by the ultrasonic beam is absorbed by the treated area, leading to rapid heating effects, which can raise the temperature of the treated tissue to $80^{\circ} \mathrm{C}$ in a few seconds [23]. This instant heating leads to coagulative necrosis through protein denaturation $[15,24]$. A recent study considered the treated area to have been successfully ablated once a minimum temperature of $65^{\circ} \mathrm{C}$ had been reached [25].

The typical devices used for HIFU treatment of the prostate are applied transrectally and so possess the advantage over other focal therapies in that an invasive surgical approach is not required. There are two devices currently available for HIFU: Sonablate and Ablatherm. Taking Sonablate as an example, the device utilizes a $4 \mathrm{MHz}$ transducer which is capable of both treatment and imaging depending upon the intensity applied, with intensities of up to $2000 \mathrm{~W} \mathrm{~cm}^{-2}$ achievable at focal lengths as short as $3 \mathrm{~cm}$ [26]. Due to the extremely high intensities involved in the procedure, there is a need for accurate monitoring of the energy delivery to, and resulting temperature of, the target tissue. In recent years, the effectiveness of real-time magnetic resonance imaging (MRI) has improved, such that it constitutes an invaluable tool for the monitoring of the HIFU procedure $[25,27]$.

The difficulty with treating enlarged prostates lies mainly in limitations on the focal length of the ultrasound probe [22, 28]. A transurethral resection of the prostate (TURP) procedure is recommended prior to treatment to reduce organ volume, as post-HIFU swelling of the prostate is common $[8,29]$. The effective treatment of anterior prostate tumours is also problematic using HIFU, as anterior perirectal fat tissue can prevent intended penetration depth of the ultrasound beam [30]. This occurs due to reflection of the signal and is a particular problem if the patient is overweight [31].

2.2. Photo-Dynamic Therapy. Photodynamic therapy (PDT) damages tissues in a highly localized fashion by exciting photosensitizing drugs with light. The drugs are administered either orally or intravenously, absorb energy from a light source, for example a laser, and transfer it to molecular oxygen residing in the surrounding tissues [32]. This in turn produces an activated form of molecular oxygen [33] known as singlet delta oxygen $\left({ }^{1} \mathrm{O}_{2}, \mathrm{SDO}\right)$. It is believed that SDO is predominantly produced following the excitation of the sensitizing agent from its triplet ground state, upon irradiation from the light source [34]. SDO is highly toxic to cells and can interfere with cell signalling as well as inducing cellular stress [35-37]. Importantly, the photosensitizing process is recurrent, eliminating the need for repeated applications during delivery as a stream of SDO is produced [33]. In addition, PDT has the advantage of greater selectivity versus other cancer therapies, as only simultaneous exposure to the photosensitizing drug, light, and oxygen will result in a cytotoxic effect on the treated cells [34]. This selectivity can be further improved by the use of an antibody, applied in conjunction with the photosensitizer, which is specific to the tumour $[38,39]$.

PDT predominantly utilizes two approaches to damage cancerous tissue. Either tumour hypoxia can be induced following laser targeting of the blood supply to the tumour or an apoptotic/necrotic response can be initiated following direct targeting of the tumour surface itself [40]. It is necessary to protect the skin and eyes of the patient, even following treatment. Such protection may be required for a few hours up to several weeks, depending on the photosensitizer used [41], as the time each drug remains in the patient's bloodstream varies vastly. A transperineal approach allows treatment of tumours localized to anterior prostate [42], giving advantages over other treatment approaches such as HIFU (see Table 1), although this can still be problematic [7]. However, PDT has the advantage of being potentially applicable at the same treatment site multiple times [42], unlike for instance surgery or radiotherapy, in addition to being a potential salvage therapy following failure of these techniques [43].

2.3. Cryotherapy. Rapid freezing and thawing cycles are employed by cryotherapy techniques in order to cause localized cellular destruction due to either the extremely low temperature alone, the rapid rate of cooling, or the period of time for which the tissue stays frozen [21]. Either liquid nitrogen or argon gas is administered to the prostate transperineally via cryoprobes under transrectal ultrasound (TRUS) guidance. Argon gas probes are now favoured over liquid nitrogen based approaches due their thinner diameters, permitting the insertion of additional probes (in a brachytherapy-like manner) to improve the efficacy of treatment [44]. In addition, the use of argon gas dramatically improves the freeze-thaw effect by reducing the probe tip to a temperature of $-187^{\circ} \mathrm{C}$, before $67^{\circ} \mathrm{C}$ helium gas rapidly thaws the treated region [44, 45], causing rupturing and bursting of the cells. Two cycles, reaching at least $-40^{\circ} \mathrm{C}$ are required for complete cell death, with cell shrinkage and protein denaturation occurring as the tissue temperature decreases beyond $0^{\circ} \mathrm{C}$ [21]. A urethral warming catheter and multiple thermosensors are typically used to prevent freezing of unwanted regions $[45,46]$.

Cryotherapy can be applied as a salvage therapy, for example, after the failure of or recurrence following radio- and 
TABLE 1: Pros and cons of focal therapies currently available for prostate cancer.

\begin{tabular}{|c|c|c|}
\hline Treatment & Summary of Pros & Summary of Cons \\
\hline $\begin{array}{l}\text { High-intensity } \\
\text { focused ultrasound }\end{array}$ & $\begin{array}{l}\text { (i) Transrectal application negates the need for } \\
\text { surgical approach } \\
\text { (ii) Improvements in MRI technology allow } \\
\text { real-time procedure monitoring and improved } \\
\text { targeting }\end{array}$ & $\begin{array}{l}\text { (i) Difficulty treating enlarged prostates, especially } \\
\text { in overweight patients } \\
\text { (ii) Effective treatment of anterior tumours is not } \\
\text { achievable }\end{array}$ \\
\hline $\begin{array}{l}\text { Photodynamic } \\
\text { therapy }\end{array}$ & $\begin{array}{l}\text { (i) More selective than other focal therapies due to } \\
\text { conditions needed for SDO production } \\
\text { (ii) Can be applied at the same treatment site } \\
\text { multiple times }\end{array}$ & $\begin{array}{l}\text { Photosensitizing agent remains in patient's } \\
\text { bloodstream following treatment, requiring } \\
\text { protection of the eyes and skin for potentially } \\
\text { weeks after the procedure }\end{array}$ \\
\hline Cryotherapy & $\begin{array}{l}\text { (i) Double freeze-thaw cycle effectively destroys } \\
\text { cells in targeted region } \\
\text { (ii) Can be applied as a salvage following } \\
\text { radiotherapy techniques }\end{array}$ & $\begin{array}{l}\text { (i) Urinary infections and perineal discomfort } \\
\text { posttreatment are common } \\
\text { (ii) Relatively invasive treatment, with added } \\
\text { needed for thermal protection of urethra, bladder } \\
\text { and rectum }\end{array}$ \\
\hline Radiotherapy & $\begin{array}{l}\text { (i) Minimally invasive approach as radiation is } \\
\text { usually applied externally } \\
\text { (ii) Proton beam therapy and Cyberknife } \\
\text { technologies give hope of improved targeting with } \\
\text { fewer side effects }\end{array}$ & $\begin{array}{l}\text { (i) Many side effects as a result of radiation at } \\
\text { unintended sites, causing urinary incontinence, } \\
\text { rectal pain, and erectile dysfunction } \\
\text { (ii) A third of patients experience radiorecurrent } \\
\text { disease }\end{array}$ \\
\hline Brachytherapy & $\begin{array}{l}\text { Image guided seed placement allows effective } \\
\text { treatment of localized areas }\end{array}$ & $\begin{array}{l}\text { Needle array application is a highly invasive } \\
\text { process }\end{array}$ \\
\hline
\end{tabular}

brachytherapy [47, 48]. Common side effects following cryotherapy include rectal or perineal discomfort [49] and urinary infections [50]. Major complications can include rectourethral fistula, although this is rare [45].

2.4. Radiotherapy. Whilst radiotherapy is not considered a focal therapy, variants such as Cyberknife and brachytherapy have the potential to be applied to more localized cancers and are discussed later in this section. It has long been known that ionizing radiation (IR) can lead to adverse effects on cells. Using this principle, effects include, but are not limited to DNA damage, cell cycle arrest, and ultimately cell death can be achieved through radiotherapy [51]. This is due to reactive oxygen species (ROS) formed from interactions with free radicals, produced as a result of multiple ionizations via the Compton effect [52]. Radical formation is believed to take place in discrete regions [51], with so-called "clustered" DNA damage necessary in order to produce a potentially lethal cellular effect $[53,54]$. However, it has been shown that cancer stem cells (CSCs), which are thought to instigate cancerous growth [55], can be resistant to radiological techniques, as well as promoting cancer recurrence following treatment $[56,57]$. Indeed, prostate stem-like cells in epithelial cultures derived from patient samples are more radioresistant than more differentiated cells, due to increased levels of heterochromatin conferring a protective effect [58].

Some studies have suggested that at least $74 \mathrm{~Gy}$, and indeed upwards of $80 \mathrm{~Gy}$ [59], should be applied in the case of localized prostate cancer, as patients treated with less than $72 \mathrm{~Gy}$ have shown higher cancer recurrence rates [60]. The total dose is usually delivered in multiple smaller fractions of, for example, $2 \mathrm{~Gy}$ per day for 60 days, not including weekends [61]. Following treatment, patients may often experience side effects including but not limited to urinary incontinence, diarrhoea, and rectal discomfort. Urinary problems can persist or present at longer time periods following initial treatment, as well as erectile dysfunction $[62,63]$. In addition, and most worryingly, a third of patients experience radiorecurrent disease [64].

Different techniques are available, whereby the radiation is either deposited externally or internally. For the external treatment of tumours, the most applied therapy is external beam radiotherapy (EBRT), where the cancerous area is treated by a focused beam of IR. This relies on precise beam alignment with the targeted area, in order to maximize treatment efficacy and minimize collateral damage to surrounding healthy tissue. Several variants of EBRT are being pursued and constantly developed, including three-dimensional conformal radiotherapy (3D-CRT) and intensity-modulated radiation therapy (IMRT), which aim to utilize improvements in imaging technology to satisfy the aforementioned criteria for most effective treatment [65].

Other approaches for the radiological treatment of prostate cancer exist, which rely on the underlying principles of IR, including proton beam therapy. Proton beam therapy has the advantage that protons deliver their energy at the end of the particle's path in the tissue compared to photons which deliver radiation along their path in the tissue [66]. The focal nature of the energy delivery in proton beam therapy could in theory mean that untargeted areas are left unharmed [67]. However, a recent study indicated that damage to irradiated tissues outside of the target area is less severe following IMRT [68], in addition to being of lower cost than proton beam therapy. As such, questions still remain as to the efficacy and effectiveness of proton beam therapy as a focal technique. 
Another recent development, which seeks to improve localization of radiotherapy compared to EBRT, is hypofractionated stereotactic body radiation therapy (SBRT) via the Cyberknife linear accelerator machine. A unique feature of prostate cancer is its low " $\alpha / \beta$ ratio," which represents nonrepairable versus repairable cellular damage,respectively, with the $\alpha$-term linearly dependent on administered dose and the $\beta$-term to its square [69]. For this reason several studies have suggested that hypofractionated radiation doses may result in more effective treatment of localized tumours [69-72]. During Cyberknife SBRT movement of the prostate is detected and automatically corrected for during the procedure by the robotic arm [73], enabling delivery of the radiation to be directed within $2 \mathrm{~mm}$ of the target area [74]. This enables the Cyberknife to deliver a hypofractionated radiation dose more accurately and noninvasively to the tumour [73] than conventional EBRT. Another major advantage of SBRT over EBRT is that treatments are usually delivered over a few days rather than weeks, rendering posttreatment hospitalization unnecessary [73]. However, SBRT treatment results in similar side-effects to those experienced following conventional radiotherapy. Rectal and urinary complications have been reported, in addition to erectile dysfunction [70], although the levels of these have been proposed as within acceptable limits [75]. In addition, the cost of Cyberknife technology is more expensive than other radiological techniques, at least in terms of initial outlay [72], although this is yet to be thoroughly investigated.

An increasingly common approach for treating prostate cancer internally is brachytherapy, which uses radioisotopes such as ${ }^{125} \mathrm{I},{ }^{103} \mathrm{Pd}$, and ${ }^{131} \mathrm{Cs}$ and is typically applied in order to ablate the whole prostate gland [76]. The radioisotopes, with half-lives ranging from $\sim 10-60$ days [76] are delivered to the prostate as seeds through a matrix of narrow diameter needles inserted transperineally. Brachytherapy can either be used as a stand-alone treatment, in conjunction with radiotherapy or radical prostatectomy, or as a salvage treatment following EBRT [77].

A more recent development of brachytherapy is known as high dose rate (HDR) brachytherapy with ${ }^{192} \operatorname{Ir}$ [76], which provides a boosted dose of radiation following EBRT [78]. If administered in conjunction with utilizing imaging tools such as MRI or TRUS, radioactive seeds may be delivered to the targeted area more accurately, providing a case for HDR brachytherapy as a focal therapy [79].

2.5. Imaging: An Integral Part of Focal Therapy. All focal therapies for prostate cancer rely on accurate imaging to have maximum effect [79]. Imaging techniques are constantly advancing and are used for initial detection, determination of tumour location, staging of tumour, assessment of tumour aggressiveness, and detection of recurrences as well as identifying metastases $[80,81]$. In the context of administration of focal therapies, early detection is most critical. Since the widespread uptake of the PSA test, early detection has become more common [79].

The kinds of imaging used in prostate cancer detection, diagnosis, and treatment are TRUS to enable targeted biopsies; MRI for accurate imaging of soft tissue; positron emission tomography (PET) for detecting lymph node metastasis and bone scans; and X-rays and computerized tomography (CT) scans to assess bone metastases. To detect localized prostate cancer, TRUS and MRI are by far the most used and most useful scans.

TRUS was traditionally used to allow biopsies from predetermined sites in the prostate, following an abnormal digital rectal examination (DRE) and increased PSA, and not as a method to identify precise locations of tumour foci [82]. However, improvements to the technique, including contrast-enhanced ultrasound using microbubble contrast media, elastography to measure tissue stiffness, and Doppler ultrasound to measure blood flow, can result in more targeted biopsies, leading to improved detection and diagnosis [83, 84]. TRUS can distinguish between an outer and inner gland encompassing the central, peripheral, and transition zones, though not at the same resolution as MRI [82].

MRI is highly sensitive and is the dominant imaging modality used for focal treatment $[85,86]$. To undertake standard MRI, endorectal and pelvic phase-arrayed coils are used in conjunction to improve positioning of the prostate and to receive MR signals, respectively, resulting in clearer images with optimal signal-to-noise ratio [79]. The prostate zones are clearly visualized using MRI [87]. However, standard MRI is not accurate enough to determine precise location and diagnosis, where multiparametric MRI is required [88]. This includes diffusion-weighted imaging (DWI-MRI) that measures water diffusivity, dynamic contrast enhanced (DCEMRI), making use of a contrast agent, and proton magnetic resonance spectroscopic imaging (H MRSI) that measures metabolites (citrate, choline, creatine, and polyamines), the ratios of which change between normal and cancerous prostate [89]. The technology to allow real-time MRI-guided biopsy has also advanced, and it is conceivable that this would be the ultimate method used when administering any focal therapy, including low temperature plasma-based treatment [88, 90-92].

In order for the more sophisticated imaging procedures to become routine, there has to be access to specialized equipment and personnel (e.g., magnetic resonance physicists), which both contribute to the potentially prohibitive expense [93]. To confidently choose focal therapy as a treatment option, patients and clinicians alike have to be convinced of its effectiveness. Imaging technology and both present and future focal therapy procedures therefore need to evolve in tandem to assure focal tumour ablation.

\section{Low-Temperature Plasmas and Their Use in Biomedicine}

Low temperature plasmas are emerging as an exciting development for therapeutics. The unique properties of cold nonequilibrium plasmas have enormous potential in disease therapeutics and plasma pharmacology as drug alternatives. Applications of these plasmas range from surface sterilization and bacterial decontamination [94-99], biofilm inactivation [100-102], antimicrobial treatment in food preservation 


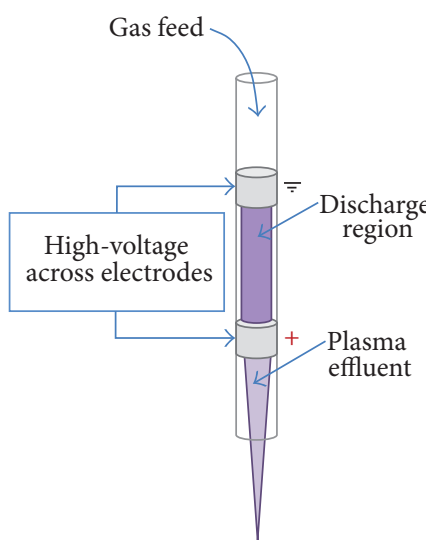

(a)

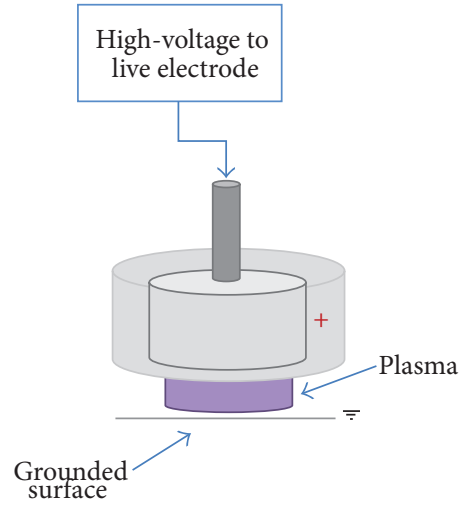

(b)

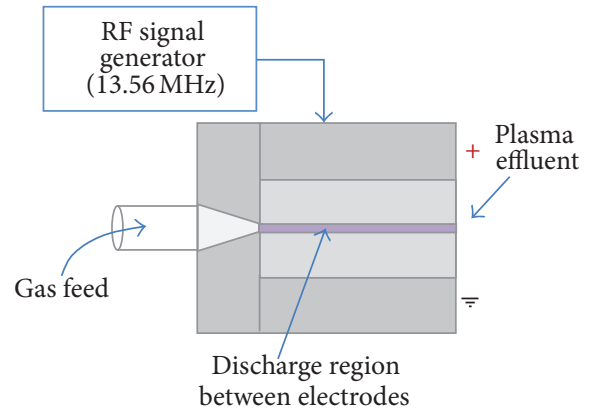

(c)

FiguRE 1: Examples of different plasma devices for medical applications. Linear-field plasma jets: (a) dielectric barrier discharge jet configuration (DBD), (b) floating-electrode DBD (FE-DBD), and cross-field plasma jets (c) radiofrequency (RF).

[103-105], and wound healing [106, 107], to cancer treatment [108-111]. This rapidly growing field of "plasma medicine" has emerged over the last 5-10 years and offers great potential, bringing together multidisciplinary branches of science and engineering.

Nonequilibrium plasmas, operated at ambient atmospheric pressure and temperature, are very efficient sources for the production of highly reactive neutral particles, for example, reactive oxygen and nitrogen species (RONS) (such as atomic oxygen [112-114], atomic nitrogen [115], hydroxyl radical, superoxide, singlet delta oxygen, and nitrogen oxides), charged particles, UV-radiation, and electromagnetic fields. Individually, many of these components have been implicated in therapeutics. RONS are known to play a crucial role in biological systems, such as signalling and generating oxidative damage to a variety of cellular components, which can ultimately lead to cell death [116119]. Graves presents a comprehensive review summary on the role of RONS of relevance for plasma applications in biology [120]. Plasmas have the advantage of delivering these simultaneously, providing potentially superior processes. The role of these plasma components, even individually, is to date not fully known and is a topic of current research. It can be anticipated that, similar to low pressure plasma processes, in for example, plasma etching or plasma deposition, synergistic mechanisms govern the plasma surface interface rather than the individual species themselves.

3.1. Methods of Plasma Formation and Production of Reactive Species. The low temperature plasma environment is actually quite remarkable. Plasmas are formed by applying a sufficiently high electric field across a region of gas such that electrons are stripped off atoms and breakdown of the gas occurs. These free electrons in the background gas are accelerated by the applied field and collide with ions and neutral gas molecules through various processes, which are discussed below. An important feature is that the electrons are not in thermodynamic equilibrium with the background gas due to the largely different masses (light electrons, heavy atoms, and molecules). The background gas is the dominating constituent and is at room temperature, while the electrons are hotter and can drive a unique reactive environment. Ions and electrons can be created through ionization, and processes such as excitation and dissociation of the background gas result in, for example, formation of metastable particles, reactive species, radicals, and also radiation. These plasmas essentially create an otherwise impossible dry, chemically reactive environment at room temperature. Until recently, atmospheric pressure plasmas have been unstable and low temperature plasmas have conventionally been operated under lower gas pressure conditions. While this approach has proven extremely beneficial, for example, in the multibillion dollar semiconductor industry, it is limiting with regard to broader exploitation of nonvacuum compatible materials. Through the use of gas flow it is now possible to sustain stable, controllable plasmas at atmospheric pressure. Reactive species can be brought from the main plasma production region, transporting energy to a surface. Here, two distinctly different plasma sources, with varying degrees of reactivity will be discussed.

Various devices are available for the formation and delivery of plasma [120-124] which rely on broadly the same principles. One variant is the dielectric barrier discharge (DBD) configuration plasma jet (Figure 1(a)). Such plasmas are produced by feeding carrier gas (e.g., helium or argon) with small oxygen admixtures (around $0.5 \%$ is typical), across a high voltage $\mathrm{kHz}$ operated supply, typically 5$30 \mathrm{kV}$, generating a discharge between two electrodes of dielectric material. Using helium as a buffer gas provides a flexible parameter space for stable homogenous operation at cold gas temperatures. The resulting plasma plume selfpropagates outwards, and as the dynamic high electric field is parallel to the direction of propagation, the jet contains reactive neutrals, charged particles, electric fields, and UV radiation (Figure 2). A variation of the DBD schematic is the floating electrode dielectric barrier discharge (FE-DBD) plasma (Figure 1(b)), which operates by using the surface 


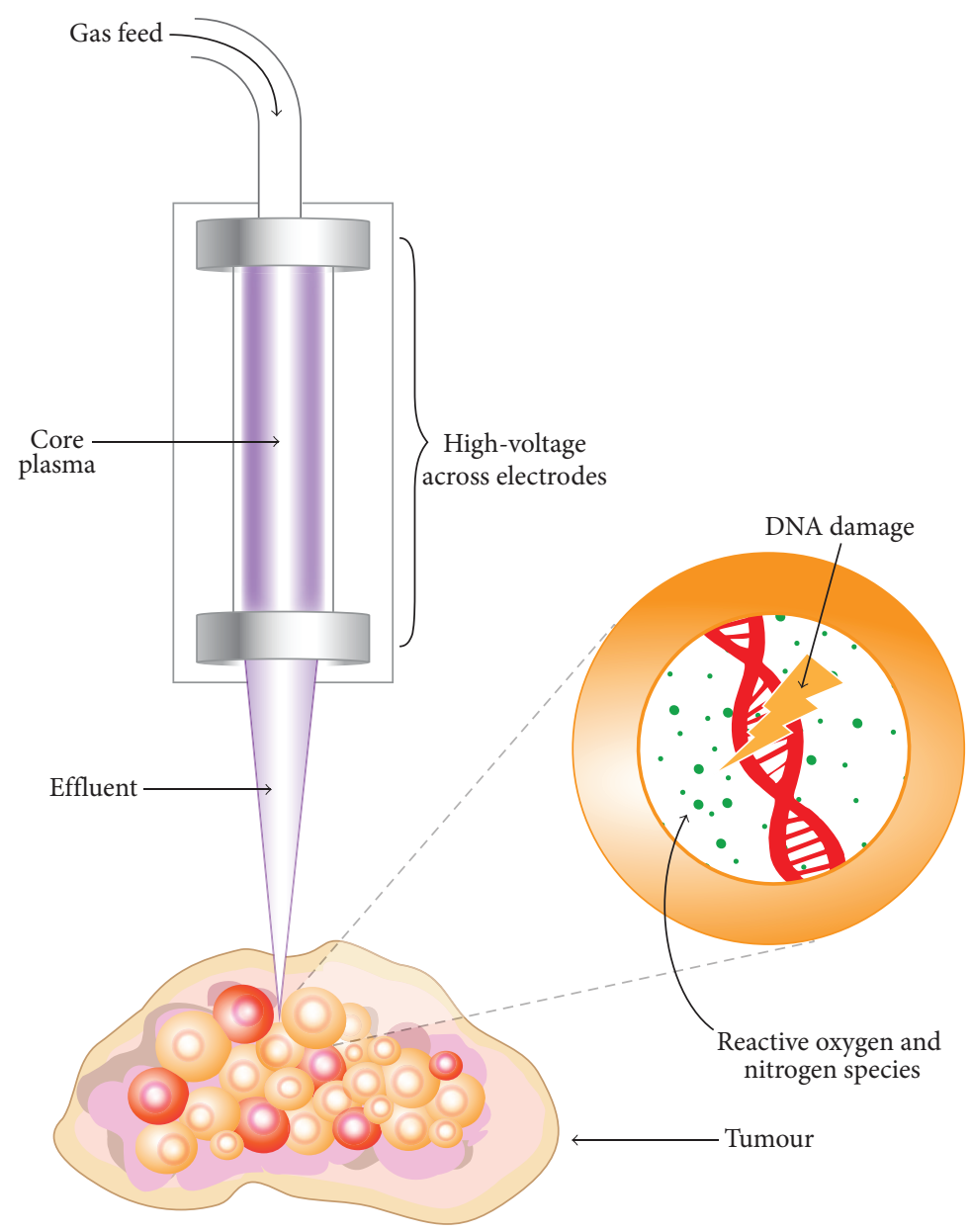

FIGURE 2: Illustrative diagram conveying the interaction of a DBD plasma jet with a cancerous tumour, leading to the induction of intracellular RONS, DNA damage, and resultant effects such as cell cycle arrest, cell death, and decreased viability.

to which it is applied as a floating counter electrode. This is possible provided that the surface has sufficient "charge storage" [94]. FE-DBD has even been applied to human skin without causing thermal damage or unwanted effects [125].

A third example of a plasma source arrangement is the radiofrequency (RF), or cross-field, plasma source (Figure 1(c)) which uses a $13.56 \mathrm{MHz}$ RF signal as a means of gas excitation. This device utilizes plane-parallel electrodes, with a gas flow passing through the core plasma volume. This particular source, unlike the DBD plasma jet, possesses a charge-free effluent since the applied electric field is perpendicular to the direction of gas-travel, thus confining charged species to the core plasma region. Due to the high collision frequency at atmospheric pressure, the effluent is devoid of charge carriers and its characteristics are dominated by energy carrying reactive neutrals. The RF plasma jet is the most comprehensively studied LTP with respect to diagnostics and modelling $[112,115,126-136]$ and is currently being developed into a reference source.

The transport of the plasma components to the targeted area is complex. In the core plasma region a large, but defined, number of species can be created (including $\mathrm{O}, \mathrm{N}, \mathrm{NO}$, and $\left.\mathrm{O}_{2}{ }^{-}\right)$. As the plasma crosses the interface with ambient air, new reactions and components are formed. Upon interaction with either humidity or liquid layers on biological samples (Figure 2) new species with varying lifetimes can be created $\left(\mathrm{OH}, \mathrm{H}, \mathrm{H}_{2} \mathrm{O}_{2}\right.$, and $\left.\mathrm{ONOO}^{-}\right)$. Energy dissipation at these interfaces is important and to date unclear. Measurements and simulations under this atmospheric pressure environment are challenging, primarily due to the multiphase (solid, liquid, gas, and plasma), strongly nonequilibrium environment with large gradients (e.g., in electric field), high collisionality thus short-lived species and micron length scales. This requires the development of many new techniques for both measurements and models. The plasma chemistry can be deliberately manipulated or optimized for a desired result by fine alterations to gas admixtures or the electron energy distribution function (EEDF) [129, 137]. Despite the multitude of work that has been conducted to diagnose and characterize the RONS produced [126-128] in addition to the ionization processes and mechanisms that occur in LTPs, these are not yet comprehensively understood.

3.2. Supporting Evidence for LTP as a Therapeutic Medical Device. As already mentioned, the potential of LTPs has been explored in many different medical areas. One highly 
active division of research is in the area of bacterial inactivation and surface sterilization. It has been shown that LTPs can damage the membranes of bacterial cells, through the interaction of reactive species, leading to the bactericidal effect [138]. Survival has been shown to be greatly reduced following LTP treatment, with a clearly defined voided region forming on the irradiated surface [139], suggesting that the interaction is mediated by short-lived reactive species [140, 141]. LTPs do not cause thermal or chemical damage to the treated surface, presenting an advantage over conventional sterilization techniques [140, 142]. Furthermore, LTPs have also been shown to be effective in the treatment of biofilms, minimizing bacterial formation posttreatment $[101,143]$ and greatly reducing cell viability even at short plasma-exposures [144]. These attributes give potential for applications in dentistry $[145,146]$.

Plasma-based bacterial inactivation has also been applied to the sterilization of chronic wounds in order to improve the rate of healing. This was shown in a recent phase II trial, which reported a significant reduction of bacterial load in the plasma treated area versus control [147, 148]. Crucially, plasma effects were localized, with no side effects (such as pain due to plasma application) reported. Another trial provided further agreement that LTP does not damage the surface of skin nor lead to dryness through exposure, with a view to antimicrobial applications [149]. It has also been found that when LTP was applied to surface wounds on the skin of mice, vastly improved blood coagulation and consequential accelerated healing resulted versus untreated wounds [106]. It was perceived that plasma-produced NO may be responsible for the improved wound response, which is in agreement with other work on NO as the key RONS in cell proliferation and wound healing [150-154]. Another study showed improved clotting of wounds on the surface of pig skin, in addition to establishing safe operating parameters for LTP exposure [107].

Despite LTPs being earmarked as a technology for future healthcare, plasmas have been used for a range of surgical applications in the field of electrosurgery since as long ago as $1991[155,156]$. Though not technically a LTP, the argon plasma coagulator (APC) has been employed in various surgical disciplines for the purposes of tissue removal and wound cauterization [155] and is perceived as an improvement on existing laser-based techniques [157]. Recently, plasma vaporization has been applied to benign prostate hyperplasia $(\mathrm{BPH})$, with the hope of reducing the common side effects of conventional transurethral resection of the prostate (TURP) procedures [158]. Early results show that the concept of plasma vaporization could prove to be a significant improvement over current TURP techniques [159] for BPH, with reduced complications [160].

In recent years, investigations have been performed into the interaction of LTPs with different types of cancer cells, including melanoma [161-163], ovarian [164], colorectal [165], liver [166], lung [110], breast [167], and brain [168] amongst others. The gold standard for LTP as a cancer therapy has to be the selective cytocidal targeting of cancerous tissue, whilst leaving healthy tissues unaffected. The effect of reactive species produced by plasma treatment has been extensively studied in vitro, with plasma induced DNA damage and apoptosis has been investigated [108, 169]. Another investigation showed the same response due to cellular detachment [170]. A considerable reduction in cell viability has been demonstrated using the MTT assay, as a result of high nitric $\mathrm{NO}$ and ROS concentrations [109]. It has also been suggested that immediate cell death can be caused by sufficiently high plasma doses, following minimal cell survival after extended plasma exposure [171]. LTP has also been applied in vivo to treat mice with tumours derived from glioma cell lines, where a preliminary study showed a reduction in tumour volume of over $50 \%$ at six days following initial plasma treatment [172]. Survival rates of plasma-treated mice increased by over half, compared with the control group who received no treatment [172]. In a follow-up study, ROS produced by the plasma were earmarked as the main antitumour agents, with evidence for cell cycle targeting [173] and apoptosis also presented [174-176]. LTP has also been recently applied to ablate tumours in mice subcutaneously injected with neuroblastoma cells, with a reduction in the rate of tumour growth observed versus control. In addition, survival time posttreatment almost doubled [177]. Another means of LTPcellular interaction is the electric field that is generated at the effluent tip of DBD jet devices. This may lead to the phenomenon of irreversible cellular electroporation, which has been shown to cause tumour regression and cell death in its own right [178-180] and may aid the transport of RONS to the cell nucleus.

Despite LTP-based approaches demonstrating considerable promise in cancer treatment, further focussed work on the exact mechanisms of plasma-cellular interaction is required before such a technique could be used therapeutically. This includes primarily the quantification of which reactive species are causing adverse cellular effects, tailoring the plasma to deliver maximum damage to the cancer, before developing practical apparatus for patient treatment in the operating theatre. This process may be aided by the use of plasma in combination with radiological and chemotherapeutic techniques [181], in order to increase efficacy.

\section{Low-Temperature Plasma as a Focal Therapy for Prostate Cancer}

At the time of writing, no published study exists on the application of LTP to prostate cancer. The following section outlines how LTPs could be utilized as a focal therapy in practice, how LTPs might compare to other conventional focal therapies for prostate cancer in terms of efficacy, and what might be the upper limit of disease stage for treatment of localized cancer with LTP.

4.1. Methods of Treatment Delivery and Plasma "Dose". Application of LTP to a patient has been successfully applied clinically by treatment of the skin with the FE-DBD system mentioned earlier [125]. Clearly, delivery to the prostate represents a more complex technical challenge. Probably the most efficient means of application would be to follow the approach of PDT and brachytherapy by inserting the 


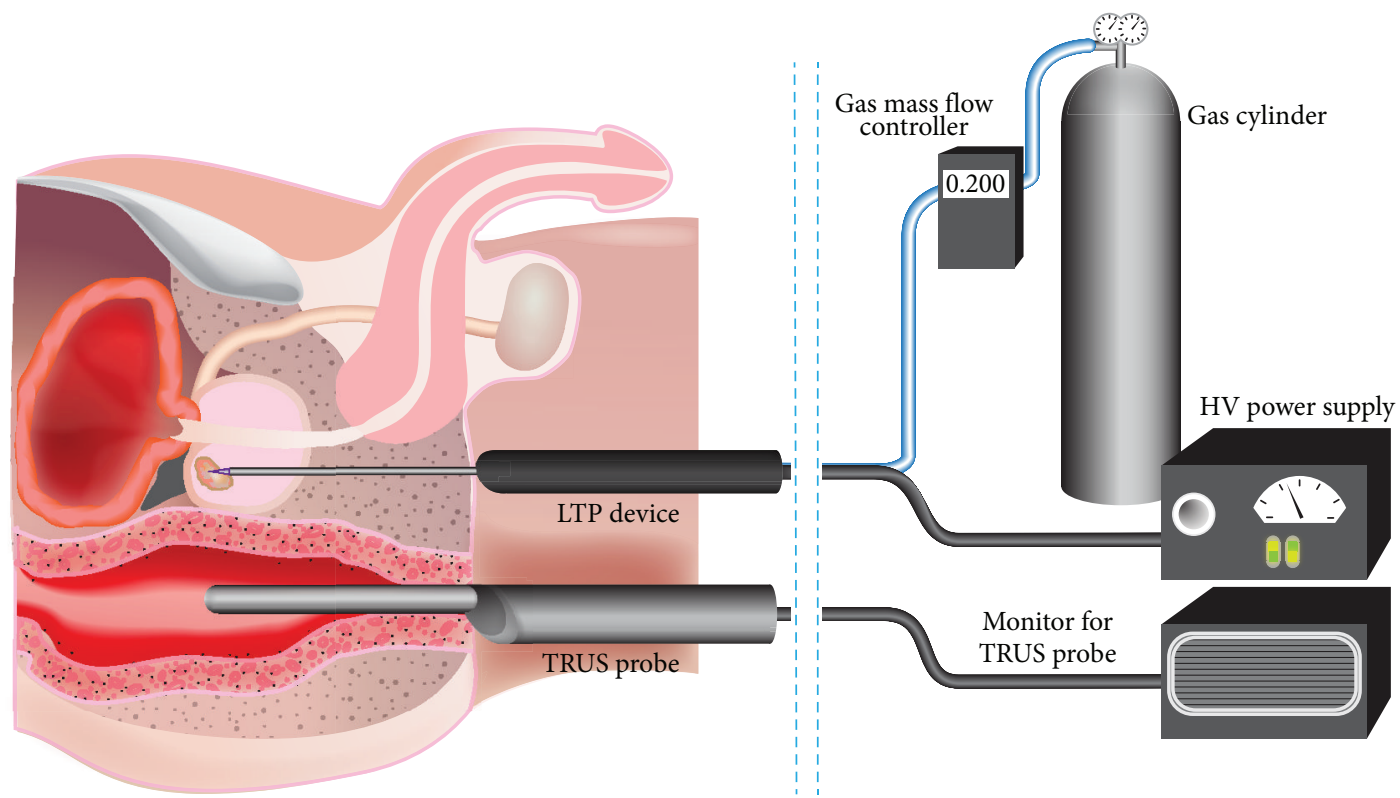

FIGURE 3: Proposed treatment approach for LTP treatment of localized prostate cancer. The LTP device is administered transperineally to an organ confined prostate cancer. Supporting image guidance from a TRUS probe, along with high-voltage (HV) power supply and gas flow-rate control are shown.

plasma transperineally to provide a focal treatment of organ confined cancers. In reality, whichever way LTP is applied, there is an obvious common dependence on accurate imaging techniques, as discussed in Section 2.5. With simultaneous image guidance by means of TRUS, following prior MRI scan, it is conceivable that LTP could be applied to localized tumours. A representation of one potential treatment delivery system is outlined in Figure 3.

DBD configuration plasma jet devices have already been fabricated and delivered via flexible optical fibres for the treatment of carcinoma, with outer diameters as fine as $60 \mu \mathrm{m}$ [110].

One of the most important factors for LTP as a cancer therapy is a thorough understanding of the species produced and their concentration for each particular type of device. Correlating the concentration of produced species to a known plasma "dose" is crucial, as lower doses and exposures can stimulate a proliferative response in cells $[182,183]$. For LTP therapy to be accepted clinically, there first needs to be agreement on what constitutes the units of plasma "dose." At present, independent research groups use different devices with different operating parameters (such as those outlined in Figure 1, amongst others), with varying exposure times. Such an agreement would lead to directly comparable data across institutions, which may accelerate the route to the clinic, and thus the patient.

\subsection{Proposed Efficacy as Compared to Other Therapies. Given} that plasma induces ROS, one obvious comparison to current cancer therapies is with radiotherapy, in that both are forms of ionizing radiation that produce reactive species. Besides the lack of a need for radioactive materials, another advantage that LTP possesses over radiotherapy is the production of reactive nitrogen species (RNS) in addition to ROS. As mentioned in Section 3.2, high concentrations of NO have been shown to have a considerable detrimental effect on cell viability, induce apoptosis [184], and have the potential to cause cytostasis in tumour cells [185]. In addition, the production of peroxynitrite $\left(\mathrm{ONOO}^{-}\right)$formed as a result of reactions between superoxide $\left(\mathrm{O}_{2}^{-}\right)$and $\mathrm{NO}$ has been shown to cause DNA damage and oxidation of proteins [186, 187]. Some recent diagnostic studies have demonstrated the production of the radical singlet-delta oxygen by LTPs [188-190], which suggests similarities between LTP treatment and PDT. LTP, however, has the advantage of SDO production in addition to a range of other reactive species with cytotoxic effects.

There is some evidence to suggest that LTP may offer a selective kill of cancerous cells [164, 191-193], which offers a potential advantage over conventional radiological techniques, where unwanted damage to surrounding tissues is the main concern. However, this selectivity is yet to be definitively proven. Furthermore, due to the ambient temperature of the plasma, there should be no requirement for the probes employed by cryoablation (which monitor and regulate the temperature of the urethra and bladder), as thermal effects to the neighbouring tissues should not be of concern. This could offer a more simplified treatment procedure, targeting the tumour bed preferentially.

4.3. When to Treat with LTP? In terms of patient selection for treatment with LTP, similar criteria to current focal therapies would be applied [194]. Patients with low risk cancer (Gleason 6) are likely to opt for active surveillance to avoid unnecessary invasive procedures [195]. Patients with metastatic or locally advanced prostate cancer (typically Gleason 8-10) are not generally considered for focal therapy, as stated in Section 2. 
Therefore, the final group with intermediate risk prostate cancer would be candidates for LTP therapy. These patients are likely to have a predicted life expectancy of more than five years, with no detection of locally advanced disease using imaging technologies (clinical stage T2a or lower) $[43,196]$. Their cancer is likely to be Gleason 7 (although some localized cancer could be Gleason 8) and their PSA should be low (less than $10-20 \mathrm{ng} / \mathrm{mL}$ ). The other consideration for treatment is whether the tumour is unifocal or multifocal, thereby perhaps necessitating more than one treatment probe. 3D mapping of biopsies should assist in identification of the location, number, and size of tumour foci [197]. Fewer well-defined tumour foci would be logistically easier to treat than multiple foci. Ultimately, such focal therapy treatment is a good option for patients who do not like the uncertainty of watchful waiting but do not want to suffer the side effects of aggressive overtreatment for a low risk cancer.

\section{Conclusions}

In this review we have analysed some of the currently available focal therapies for localized prostate cancer and where their advantages and limitations lie. We propose that the emerging field of low temperature plasmas may offer an alternative and viable solution to the effective treatment of prostate cancer, with minimal side effects and improved treatment efficacy versus other focal therapies. However, for this promising concept to become a reality, further study must be undertaken in order to fully diagnose the cellular interaction mechanisms of the plasma, and also how surgical administration would occur, a means of which has been suggested here. In addition, there is a need for continued development of imaging diagnostics, upon which a plasmabased approach would rely for precise application.

\section{Conflict of Interests}

The authors declare that there is no conflict of interests regarding the publication of this paper.

\section{Authors' Contribution}

Norman J. Maitland and Deborah O'Connell contributed equally to this work.

\section{Acknowledgments}

This work was part-funded by the Wellcome Trust [ref: 097829/Z/11/A], the UK EPSRC through a Career Acceleration Fellowship (EP/H003797/1) and a Manufacturing Grant (EP/K018388/1). The authors wish to acknowledge funding from Yorkshire Cancer Research (YCR-Y257PA). Finally, the authors would like to thank Phil Roberts for his assistance with the diagrams presented in this paper.

\section{References}

[1] A. Jemal, F. Bray, M. M. Center, J. Ferlay, E. Ward, and D. Forman, "Global cancer statistics," CA Cancer Journal for Clinicians, vol. 61, no. 2, pp. 69-90, 2011.
[2] J. Li, J. A. Djenaba, A. Soman et al., "Recent trends in prostate cancer incidence by age, cancer stage, and grade, the United States, 2001-2007," Prostate Cancer, vol. 2012, Article ID 691380, 8 pages, 2012.

[3] H. Lepor, "Pathophysiology, epidemiology, and natural history of benign prostatic hyperplasia," Reviews in Urology, vol. 6, supplement 9, pp. S3-S10, 2004.

[4] J. Ansari, S. A. Hussain, A. Zarkar, J. S. Tanguay, J. Bliss, and J. Glaholm, "Docetaxel chemotherapy for metastatic hormone refractory prostate cancer as first-line palliative chemotherapy and subsequent re-treatment: birmingham experience," Oncology Reports, vol. 20, no. 4, pp. 891-896, 2008.

[5] P. Chris and O. Sartor, "Abiraterone and increased survival in metastatic prostate cancer," The New England Journal of Medicine, vol. 364, pp. 1995-2005, 2011.

[6] D. L. Berry, C. M. Moinpour, C. S. Jiang et al., "Quality of life and pain in advanced stage prostate cancer: results of a Southwest Oncology Group randomized trial comparing docetaxel and estramustine to mitoxantrone and prednisone," Journal of Clinical Oncology, vol. 24, no. 18, pp. 2828-2835, 2006.

[7] G. Bozzini, P. Colin, P. Nevoux et al., "Focal therapy of prostate cancer: energies and procedures," Urologic Oncology, vol. 31, no. 2, pp. 155-167, 2013.

[8] L. Mearini and M. Porena, “Transrectal high-intensity focused ultrasound for the treatment of prostate cancer: past, present, and future," Indian Journal of Urology, vol. 26, no. 1, pp. 4-11, 2010.

[9] G. Duchesne, "Localised prostate cancer: current treatment options," Australian Family Physician, vol. 40, no. 10, pp. 768$771,2011$.

[10] L. Klotz, "Active surveillance versus radical treatment for favorable-risk localized prostate cancer," Current Treatment Options in Oncology, vol. 7, no. 5, pp. 355-362, 2006.

[11] M. A. Kollmeier and M. J. Zelefsky, "How to select the optimal therapy for early-stage prostate cancer," Critical Reviews in Oncology/Hematology, vol. 83, no. 2, pp. 225-234, 2012.

[12] J. L. Stanford, Z. Feng, A. S. Hamilton et al., "Urinary and sexual function after radical prostatectomy for clinically localized prostate cancer: the prostate cancer outcomes study," Journal of the American Medical Association, vol. 283, no. 3, pp. 354-360, 2000.

[13] M. Bul, R. C. van den Bergh, X. Zhu et al., "Outcomes of initially expectantly managed patients with low or intermediate risk screen-detected localized prostate cancer," BJU International, vol. 110, no. 11, pp. 1672-1677, 2012.

[14] M. Bul, X. Zhu, R. Valdagni et al., "Active surveillance for lowrisk prostate cancer worldwide: the PRIAS study," European Urology, vol. 63, no. 4, pp. 597-603, 2013.

[15] U. Lindner, J. Trachtenberg, and N. Lawrentschuk, "Focal therapy in prostate cancer: modalities, findings and future considerations," Nature Reviews Urology, vol. 7, no. 10, pp. 562$571,2010$.

[16] V. Kasivisvanathan, M. Emberton, and H. U. Ahmed, "Focal therapy for prostate cancer: rationale and treatment opportunities," Clinical Oncology, vol. 25, no. 8, pp. 461-473, 2013.

[17] S. Eggener, G. Salomon, P. T. Scardino, J. De la Rosette, T. J. Polascik, and S. Brewster, "Focal therapy for prostate cancer: possibilities and limitations," European Urology, vol. 58, no. 1, pp. 57-64, 2010.

[18] M. Valerio, H. U. Ahmed, M. Emberton et al., "The role of focal therapy in the management of localised prostate cancer: a systematic review," European Urology, 2013. 
[19] R. Bihrle, R. S. Foster, N. T. Sanghvi, J. P. Donohue, and P. J. Hood, "High intensity focused ultrasound for the treatment of benign prostatic hyperplasia: early United States clinical experience," Journal of Urology, vol. 151, no. 5, pp. 1271-1275, 1994.

[20] S. Madersbacher, M. Pedevilla, L. Vingers, M. Susani, and M. Marberger, "Effect of high-intensity focused ultrasound on human prostate cancer in vivo," Cancer Research, vol. 55, no. 15, pp. 3346-3351, 1995.

[21] T. Nomura and H. Mimata, "Focal therapy in the management of prostate cancer: an emerging approach for localized prostate cancer," Advances in Urology, vol. 2012, Article ID 391437, 8 pages, 2012.

[22] E. R. Cordeiro, X. Cathelineau, S. Thüroff et al., "High-intensity focused ultrasound (HIFU) for definitive treatment of prostate cancer," BJU International, vol. 110, no. 9, pp. 1228-1242, 2012.

[23] G. R. Ter Haar, R. L. Clarke, M. G. Vaughan, and C. R. Hill, "Trackless surgery using focused ultrasound: technique and case report," Minimally Invasive Therapy, vol. 1, no. 1, pp. 13-19, 1991.

[24] F. Orsi, P. Arnone, W. Chen, and L. Zhang, "High intensity focused ultrasound ablation: a new therapeutic option for solid tumors," Journal of Cancer Research and Therapeutics, vol. 6, no. 4, pp. 414-420, 2010.

[25] A. Napoli, M. Anzidei, C. De Nunzio et al., "Real-time magnetic resonance-guided high-intensity focused ultrasound focal therapy for localised prostate cancer: preliminary experience," European Urology, vol. 63, no. 2, pp. 395-398, 2013.

[26] S. Madersbacher, C. Kratzik, N. Szabo, M. Susani, L. Vingers, and M. Marberger, "Tissue ablation in benign prostatic hyperplasia with high-intensity focused ultrasound," European Urology, vol. 23, no. 1, pp. 39-43, 1993.

[27] J. G. Bomers, J. P. Sedelaar, J. O. Barentsz et al., "MRI-guided interventions for the treatment of prostate cancer," American Journal of Roentgenology, vol. 199, no. 4, pp. 714-720, 2012.

[28] A. B. El Fegoun, E. Barret, D. Prapotnich et al., "Focal therapy with high-intensity focused ultrasound for prostate cancer in the elderly. A feasibility study with 10 years follow-up," International Brazilian Journal of Urology, vol. 37, no. 2, pp. 213222, 2011.

[29] C. Chaussy and S. Thüroff, "The status of high-intensity focused ultrasound in the treatment of localized prostate cancer and the impact of a combined resection," Current Urology Reports, vol. 4, no. 3, pp. 248-252, 2003.

[30] G. M. Spencer, D. J. Rubens, and D. J. Roach, "Hypoechoic fat: a sonographic pitfall," American Journal of Roentgenology, vol. 164, no. 5, pp. 1277-1280, 1995.

[31] M. Sumitomo, J. Asakuma, H. Yoshii et al., "Anterior perirectal fat tissue thickness is a strong predictor of recurrence after highintensity focused ultrasound for prostate cancer," International Journal of Urology, vol. 17, no. 9, pp. 776-782, 2010.

[32] T. Liu, L. Y. Wu, J. K. Choi, and C. E. Berkman, “Targeted photodynamic therapy for prostate cancer: inducing apoptosis via activation of the caspase-8/-3 cascade pathway," International Journal of Oncology, vol. 36, no. 4, pp. 777-784, 2010.

[33] S. B. Brown, E. A. Brown, and I. Walker, "The present and future role of photodynamic therapy in cancer treatment," The Lancet Oncology, vol. 5, no. 8, pp. 497-508, 2004.

[34] W. M. Sharman, C. M. Allen, and J. E. Van Lier, "Photodynamic therapeutics: basic principles and clinical applications," Drug Discovery Today, vol. 4, no. 11, pp. 507-517, 1999.
[35] L.-O. Klotz, K.-D. Kröncke, and H. Sies, "Singlet oxygeninduced signaling effects in mammalian cells," Photochemical and Photobiological Sciences, vol. 2, no. 2, pp. 88-94, 2003.

[36] L. J. Schiff, W. C. Eisenberg, J. Dziuba, K. Taylor, and S. J. Moore, "Cytotoxic effects of singlet oxygen," Environmental Health Perspectives, vol. 76, pp. 199-203, 1987.

[37] K. Briviba, L.-O. Klotz, and H. Sies, “Toxic and signaling effects of photochemically or chemically generated singlet oxygen in biological systems," Biological Chemistry, vol. 378, no. 11, pp. 1259-1265, 1997.

[38] W. M. Sharman, J. E. Van Lier, and C. M. Allen, "Targeted photodynamic therapy via receptor mediated delivery systems," Advanced Drug Delivery Reviews, vol. 56, no. 1, pp. 53-76, 2004.

[39] A. J. Bullous, C. M. A. Alonso, and R. W. Boyle, "Photosensitiser-antibody conjugates for photodynamic therapy," Photochemical and Photobiological Sciences, vol. 10, no. 5, pp. 721-750, 2011.

[40] N. L. Oleinick, R. L. Morris, and I. Belichenko, "The role of apoptosis in response to photodynamic therapy: what, where, why, and how," Photochemical and Photobiological Sciences, vol. 1, no. 1, pp. 1-21, 2002.

[41] C. M. Moore, M. Emberton, and S. G. Bown, "Photodynamic therapy for prostate cancer-an emerging approach for organconfined disease," Lasers in Surgery and Medicine, vol. 43, no. 7, pp. 768-775, 2011.

[42] N. Arumainayagam, C. M. Moore, H. U. Ahmed, and M. Emberton, "Photodynamic therapy for focal ablation of the prostate," World Journal of Urology, vol. 28, no. 5, pp. 571-576, 2010.

[43] H. Lepor, "Vascular targeted photodynamic therapy for localized prostate cancer," Reviews in Urology, vol. 10, no. 4, pp. 254261, 2008.

[44] A. Zisman, A. J. Pantuck, J. K. Cohen, and A. S. Belldegrun, "Prostate cryoablation using direct transperineal placement of ultrathin probes through a 17-gauge brachytherapy templatetechnique and preliminary results," Urology, vol. 58, no. 6, pp. 988-993, 2001.

[45] A. De La Taille, M. C. Benson, E. Bagiella et al., "Cryoablation for clinically localized prostate cancer using an argon-based system: complication rates and biochemical recurrence," $B J U$ International, vol. 85, no. 3, pp. 281-286, 2000.

[46] J. K. Cohen and R. J. Miller, "Thermal protection of urethra during cryosurgery of prostate," Cryobiology, vol. 31, no. 3, pp. 313-316, 1994.

[47] P. Derakhshani, S. Neubauer, M. Braun, J. Zumbe, A. Heidenreich, and U. Engelmann, "Cryoablation of localized prostate cancer. Experience in 48 cases, PSA and biopsy results," European Urology, vol. 34, no. 3, pp. 181-187, 1998.

[48] J. L. Chin, D. Lim, and M. Abdelhady, "Review of primary and salvage cryoablation for prostate cancer," Cancer Control, vol. 14, no. 3, pp. 231-237, 2007.

[49] J. I. Izawa, K. Ajam, E. McGuire et al., "Major surgery to manage definitively severe complications of salvage cryotherapy for prostate cancer," Journal of Urology, vol. 164, no. 6, pp. 1978$1981,2000$.

[50] A. Gangi, G. Tsoumakidou, O. Abdelli et al., "Percutaneous MR-guided cryoablation of prostate cancer: initial experience," European Radiology, vol. 22, no. 8, pp. 1829-1835, 2012.

[51] D. A. Palacios, M. Miyake, and C. J. Rosser, "Radiosensitization in prostate cancer: mechanisms and targets," BMC Urology, vol. 13, no. 1, article 4, 2013. 
[52] H. E. Johns, "The physicist in cancer treatment and detection," International Journal of Radiation Oncology Biology Physics, vol. 7, no. 6, pp. 801-808, 1981.

[53] I. R. Radford, "Evidence for a general relationship between the induced level of DNA double-strand breakage and cell-killing after X-irradiation of mammalian cells," International Journal of Radiation Biology, vol. 49, no. 4, pp. 611-620, 1986.

[54] J. F. Ward, "Biochemistry of DNA lesions," Radiation Research. Supplement, vol. 8, pp. S103-S111, 1985.

[55] Y. M. Cho, Y. S. Kim, M. J. Kang, W. L. Farrar, and E. M. Hurt, "Long-term recovery of irradiated prostate cancer increases cancer stem cells," Prostate, vol. 72, no. 16, pp. 1746-1756, 2012.

[56] K. Ogawa, Y. Yoshioka, F. Isohashi et al., "Radiotherapy targeting cancer stem cells: current views and future perspectives," Anticancer Research, vol. 33, no. 3, pp. 747-754, 2013.

[57] C. Chargari, C. Moncharmont, A. Lévy et al., "Cancer stem cells, cornerstone of radioresistance and perspectives for radiosensitization: glioblastoma as an example," Bulletin du Cancerr, vol. 99, no. 12, pp. 1153-1160, 2012.

[58] F. M. Frame, D. Pellacani, A. T. Collins et al., "HDAC inhibitor confers radiosensitivity to prostate stem-like cells," British Journal of Cancer, vol. 109, pp. 3023-3033, 2013.

[59] S. Hummel, E. Simpson, P. Hemingway, M. D. Stevenson, and A. Rees, "Intensity-modulated radiotherapy for the treatment of prostate cancer: a systematic review and economic evaluation," Health Technology Assessment, vol. 14, no. 47, pp. 1-108, 2010.

[60] P. Kupelian, D. Kuban, H. Thames et al., "Improved biochemical relapse-free survival with increased external radiation doses in patients with localized prostate cancer: the combined experience of nine institutions in patients treated in 1994 and 1995," International Journal of Radiation Oncology Biology Physics, vol. 61, no. 2, pp. 415-419, 2005.

[61] Y. Trada, A. Plank, and J. Martin, "Defining a dose-response relationship for prostate external beam radiotherapy," Journal of Medical Imaging and Radiation Oncology, vol. 57, no. 2, pp. 237-246, 2013.

[62] M. J. Chen, E. Weltman, R. M. Hanriot et al., "Intensity modulated radiotherapy for localized prostate cancer: rigid compliance to dose-volume constraints as a warranty of acceptable toxicity?" Radiation Oncology, vol. 2, no. 1, article 6, 2007.

[63] I. M. Lips, H. Dehnad, C. H. van Gils, A. E. Boeken Kruger, U. A. van der Heide, and M. van Vulpen, "High-dose intensitymodulated radiotherapy for prostate cancer using daily fiducial marker-based position verification: acute and late toxicity in 331 patients," Radiation Oncology, vol. 3, no. 1, article 15, 2008.

[64] J. S. Jones, "Radiorecurrent prostate cancer: an emerging and largely mismanaged epidemic," European Urology, vol. 60, no. 3, pp. 411-412, 2011.

[65] B. S. Chera, C. Rodriguez, C. G. Morris et al., "Dosimetric comparison of three different involved nodal irradiation techniques for stage ii hodgkin's lymphoma patients: conventional radiotherapy, intensity-modulated radiotherapy, and three-dimensional proton radiotherapy," International Journal of Radiation Oncology Biology Physics, vol. 75, no. 4, pp. 11731180, 2009.

[66] J. A. Efstathiou, P. J. Gray, and A. L. Zietman, "Proton beam therapy and localised prostate cancer: current status and controversies," British Journal of Cancer, vol. 108, no. 6, pp. 12251230, 2013.

[67] P. J. Gray and J. A. Efstathiou, "Proton beam radiation therapy for prostate cancer-is the hype (and the cost) justified?" Current Urology Reports, vol. 14, no. 3, pp. 199-208, 2013.
[68] N. C. Sheets, G. H. Goldin, A.-M. Meyer et al., "Intensitymodulated radiation therapy, proton therapy, or conformal radiation therapy and morbidity and disease control in localized prostate cancer," Journal of the American Medical Association, vol. 307, no. 15, pp. 1611-1620, 2012.

[69] J. F. Fowler, "The radiobiology of prostate cancer including new aspects of fractionated radiotherapy," Acta Oncologica, vol. 44, no. 3, pp. 265-276, 2005.

[70] C. Oliai, R. Lanciano, B. Sprandio et al., "Stereotactic body radiation therapy for the primary treatment of localized prostate cancer," Journal of Radiation Oncology, vol. 2, no. 1, pp. 63-70, 2013.

[71] D. J. Brenner and E. J. Hall, "Fractionation and protraction for radiotherapy of prostate carcinoma," International Journal of Radiation Oncology Biology Physics, vol. 43, no. 5, pp. 1095-1101, 1999.

[72] T. Seisen, S. J. Drouin, V. Phé et al., "Current role of imageguided robotic radiosurgery (Cyberknife) for prostate cancer treatment," BJU International, vol. 111, no. 5, pp. 761-766, 2013.

[73] D. E. Freeman and C. R. King, "Stereotactic body radiotherapy for low-risk prostate cancer: five-year outcomes," Radiation Oncology, vol. 6, no. 1, article 3, 2011.

[74] Y. Xie, D. Djajaputra, C. R. King, S. Hossain, L. Ma, and L. Xing, "Intrafractional motion of the prostate during hypofractionated radiotherapy," International Journal of Radiation Oncology Biology Physics, vol. 72, no. 1, pp. 236-246, 2008.

[75] N. C. Townsend, B. J. Huth, W. Ding et al., "Acute toxicity after CyberKnife-delivered hypofractionated radiotherapy for treatment of prostate cancer," American Journal of Clinical Oncology, vol. 34, no. 1, pp. 6-10, 2011.

[76] D. S. Park, "Current status of brachytherapy for prostate cancer," Korean Journal of Urology, vol. 53, no. 11, pp. 743-749, 2012.

[77] P. L. Nguyen, A. V. D’Amico, A. K. Lee, and W. W. Suh, "Patient selection, cancer control, and complications after salvage local therapy for postradiation prostate-specific antigen failure: a systematic review of the literature," Cancer, vol. 110, no. 7, pp. 1417-1428, 2007.

[78] M. I. Koukourakis and S. Touloupidis, "External beam radiotherapy for prostate cancer: current position and trends," Anticancer Research, vol. 26, no. 1B, pp. 485-494, 2006.

[79] B. Turkbey, P. A. Pinto, and P. L. Choyke, "Imaging techniques for prostate cancer: implications for focal therapy," Nature Reviews Urology, vol. 6, no. 4, pp. 191-203, 2009.

[80] A. H. Hou, D. Swanson, and A. B. Barqawi, "Modalities for imaging of prostate cancer," Advances in Urology, vol. 2009, Article ID 818065, 12 pages, 2009.

[81] H. Hricak, P. L. Choyke, S. C. Eberhardt, S. A. Leibel, and P. T. Scardino, "Imaging prostate cancer: a multidisciplinary perspective," Radiology, vol. 243, no. 1, pp. 28-53, 2007.

[82] A. Abdellaoui, S. Iyengar, and S. Freeman, "Imaging in prostate cancer," Future Oncology, vol. 7, no. 5, pp. 679-691, 2011.

[83] E. J. Halpern, "Contrast-enhanced ultrasound imaging of prostate cancer," Reviews in Urology, vol. 8, supplement 1, pp. S29-S37, 2006.

[84] M. Mitterberger, W. Horninger, F. Aigner et al., "Ultrasound of the prostate," Cancer Imaging, vol. 10, pp. 40-48, 2010.

[85] J. G. Bomers, D. Yakar, C. G. Overduin et al., "MR imagingguided focal cryoablation in patients with recurrent prostate cancer," Radiology, vol. 268, no. 2, pp. 451-460, 2013.

[86] A. Oto, I. Sethi, G. Karczmar et al., "MR imaging-guided focal laser ablation for prostate cancer: phase I trial," Radiology, vol. 267, no. 3, pp. 932-940, 2013. 
[87] M. Seitz, A. Shukla-Dave, A. Bjartell et al., "Functional magnetic resonance imaging in prostate cancer," European Urology, vol. 55, no. 4, pp. 801-814, 2009.

[88] F. Cornud, N. B. Delongchamps, P. Mozer et al., "Value of multiparametric MRI in the work-up of prostate cancer," Current Urology Reports, vol. 13, no. 1, pp. 82-92, 2012.

[89] A. Shukla-Dave and H. Hricak, "Role of MRI in prostate cancer detection," NMR in Biomedicine, vol. 27, no. 1, pp. 16-24, 2014.

[90] D. G. Engehausen, K. Engelhard, S. A. Schwab et al., "Magnetic resonance image-guided biopsies with a high detection rate of prostate cancer," The Scientific World Journal, vol. 2012, Article ID 975971, 6 pages, 2012.

[91] G. Fiard, N. Hohn, J. L. Descotes et al., "Targeted MRI-guided prostate biopsies for the detection of prostate cancer: initial clinical experience with real-time 3-dimensional transrectal ultrasound guidance and magnetic resonance/transrectal ultrasound image fusion," Urology, vol. 81, no. 6, pp. 1372-1378, 2013.

[92] A. Krieger, S.-E. Song, N. Bongjoon Cho et al., "Development and evaluation of an actuated MRI-compatible robotic system for MRI-guided prostate intervention," IEEE/ASME Transactions on Mechatronics, vol. 18, no. 1, pp. 273-284, 2013.

[93] F. Pinto, A. Totaro, A. Calarco et al., "Imaging in prostate cancer diagnosis: present role and future perspectives," Urologia Internationalis, vol. 86, no. 4, pp. 373-382, 2011.

[94] G. Fridman, M. Peddinghaus, H. Ayan et al., "Blood coagulation and living tissue sterilization by floating-electrode dielectric barrier discharge in air," Plasma Chemistry and Plasma Processing, vol. 26, no. 4, pp. 425-442, 2006.

[95] G. Daeschlein, S. Scholz, R. Ahmed et al., "Skin decontamination by low-temperature atmospheric pressure plasma jet and dielectric barrier discharge plasma," Journal of Hospital Infection, vol. 81, no. 3, pp. 177-183, 2012.

[96] M. G. Kong, "A complementary sterilisation strategy using cold atmospheric plasmas," Medical Device Technology, vol. 17, no. 3, pp. 26-28, 2006.

[97] M. G. Kong, "Cold atmospheric plasma destruction of solid proteins on stainless-steel surface and on real surgical instruments," GMS Krankenhaushygiene Interdisziplinär, vol. 3, no. 1, Article ID Doc07, 2008.

[98] K. Y. Baik, Y. H. Kim, Y. Hyo et al., "Feeding-gas effects of plasma jets on escherichia coli in physiological solutions," Plasma Processes and Polymers, vol. 10, no. 3, pp. 235-242, 2013.

[99] M. Laroussi, C. Tendero, X. Lu, S. Alla, and W. L. Hynes, "Inactivation of bacteria by the plasma pencil," Plasma Processes and Polymers, vol. 3, no. 6-7, pp. 470-473, 2006.

[100] K. Fricke, I. Koban, H. Tresp et al., "Atmospheric pressure plasma: a high-performance tool for the efficient removal of biofilms," PLoS ONE, vol. 7, no. 8, Article ID e42539, 2012.

[101] M. Y. Alkawareek, Q. T. Algwari, S. P. Gorman et al., "Application of atmospheric pressure nonthermal plasma for the in vitro eradication of bacterial biofilms," Fems Immunology and Medical Microbiology, vol. 65, no. 2, pp. 381-384, 2012.

[102] J. J. Cotter, P. Maguire, F. Soberon, S. Daniels, J. P. O’Gara, and E. Casey, "Disinfection of meticillin-resistant Staphylococcus aureus and Staphylococcus epidermidis biofilms using a remote non-thermal gas plasma," Journal of Hospital Infection, vol. 78, no. 3, pp. 204-207, 2011.

[103] D. Ziuzina, S. Patil, P. J. Cullen et al., "Atmospheric cold plasma inactivation of Escherichia coli in liquid media inside a sealed package," Journal of Applied Microbiology, vol. 114, no. 3, pp. 778-787, 2013.
[104] A. Fernandez, E. Noriega, and A. Thompson, "Inactivation of Salmonella enterica serovar Typhimurium on fresh produce by cold atmospheric gas plasma technology," Food Microbiology, vol. 33, no. 1, pp. 24-29, 2013.

[105] M. Laroussi, "Nonthermal decontamination of biological media by atmospheric-pressure plasmas: review, analysis, and prospects," IEEE Transactions on Plasma Science, vol. 30, no. 4, pp. 1409-1415, 2002.

[106] E. Garcia-Alcantara, R. López-Callejas, P. R. Morales-Ramírez et al., "In vivo accelerated acute wound healing in mouse skin using combined treatment of argon and helium plasma needle," Archives of Medical Research, vol. 44, no. 3, pp. 169-177, 2013.

[107] A. S. Wu, S. Kalghatgi, D. Dobrynin et al., "Porcine intact and wounded skin responses to atmospheric nonthermal plasma," Journal of Surgical Research, vol. 179, no. 1, pp. el-e12, 2013.

[108] R. Sensenig, S. Kalghatgi, E. Cerchar et al., "Non-thermal plasma induces apoptosis in melanoma cells via production of intracellular reactive oxygen species," Annals of Biomedical Engineering, vol. 39, no. 2, pp. 674-687, 2011.

[109] X. Yan, Z. Xiong, F. Zou et al., "Plasma-induced death of HepG2 cancer cells: intracellular effects of reactive species," Plasma Processes and Polymers, vol. 9, no. 1, pp. 59-66, 2012.

[110] J. Y. Kim, J. Ballato, P. Foy et al., "Apoptosis of lung carcinoma cells induced by a flexible optical fiber-based cold microplasma," Biosensors and Bioelectronics, vol. 28, no. 1, pp. 333-338, 2011.

[111] N. K. Kaushik, Y. H. Kim, Y. G. Han et al., "Effect of jet plasma on T98G human brain cancer cells," Current Applied Physics, vol. 13, no. 1, pp. 176-180, 2013.

[112] J. Waskoenig, K. Niemi, N. Knake et al., "Atomic oxygen formation in a radio-frequency driven micro-atmospheric pressure plasma jet," Plasma Sources Science and Technology, vol. 19, no. 4, Article ID 045018, 2010.

[113] N. Knake, K. Niemi, S. Reuter, V. Schulz-von der Gathen, and J. Winter, "Absolute atomic oxygen density profiles in the discharge core of a microscale atmospheric pressure plasma jet," Applied Physics Letters, vol. 93, no. 13, Article ID 131503, 2008.

[114] N. Knake and V. Schulz-von der Gathen, "Investigations of the spatio-temporal build-up of atomic oxygen inside the microscaled atmospheric pressure plasma jet," European Physical Journal D, vol. 60, no. 3, pp. 645-652, 2010.

[115] D. Maletic, N. Puac, S. Lazović et al., "Detection of atomic oxygen and nitrogen created in a radio-frequency-driven microscale atmospheric pressure plasma jet using mass spectrometry," Plasma Physics and Controlled Fusion, vol. 54, no. 12, 2012.

[116] L. Packer and H. Sies, Eds., Methods in Enzymology, Singlet Oxygen, UV-A and Ozone, vol. 319, Academic Press, New York, NY, USA, 2000.

[117] H. Wiseman and B. Halliwell, "Damage to DNA by reactive oxygen and nitrogen species: role in inflammatory disease and progression to cancer," Biochemical Journal, vol. 313, no. 1, pp. 17-29, 1996.

[118] H. Sies, "Oxidative stress: oxidants and antioxidants," Experimental Physiology, vol. 82, no. 2, pp. 291-295, 1997.

[119] U. Bandyopadhyay, D. Das, and R. K. Banerjee, "Reactive oxygen species: oxidative damage and pathogenesis," Current Science, vol. 77, no. 5, pp. 658-666, 1999.

[120] D. B. Graves, "The emerging role of reactive oxygen and nitrogen species in redox biology and some implications for plasma applications to medicine and biology," Journal of Physics $D$, vol. 45 , no. $26,2012$. 
[121] M. Laroussi, Plasma Medicine: Applications of Low-Temperature Gas Plasmas in Medicine and Biology, Cambridge University Press, Cambridge, UK, 2012.

[122] J. Jaroslav, Q. T. Algwari, D. O’Connell et al., "Experimentalmodeling study of an atmospheric-pressure helium discharge propagating in a thin dielectric tube," Ieee Transactions on Plasma Science, vol. 40, no. 11, pp. 2912-2919, 2012.

[123] Q. T. Algwari and D. O'Connell, "Electron dynamics and plasma jet formation in a helium atmospheric pressure dielectric barrier discharge jet," Applied Physics Letters, vol. 99, no. 12, Article ID 121501, 2011.

[124] J. L. Walsh and M. G. Kong, "Contrasting characteristics of linear-field and cross-field atmospheric plasma jets," Applied Physics Letters, vol. 93, no. 11, Article ID 111501, 2008.

[125] D. U. Silverthorn and B. R. Johnson, HumAn Physiology: An Integrated Approach, Pearson Education, San Francisco, Calif, USA, 3rd edition, 2004, contributions by Bruce R. Johnson.

[126] T. Murakami, K. Niemi, T. Gans et al., "Chemical kinetics and reactive species in atmospheric pressure helium-oxygen plasmas with humid-air impurities," Plasma Sources Science \& Technology, vol. 22, no. 1, 2013.

[127] E. Wagenaars, T. Gans, D. O'Connell, and K. Niemi, “Twophoton absorption laser-induced fluorescence measurements of atomic nitrogen in a radio-frequency atmospheric-pressure plasma jet," Plasma Sources Science \& Technology, vol. 21, no. 4, 2012.

[128] K. Niemi, J. Waskoenig, N. Sadeghi, T. Gans, and D. O'Connell, "The role of helium metastable states in radio-frequency driven helium-oxygen atmospheric pressure plasma jets: measurement and numerical simulation," Plasma Sources Science and Technology, vol. 20, no. 5, Article ID 055005, 2011.

[129] C. O'Neill, J. Waskoenig, and T. Gans, “Tailoring electron energy distribution functions through energy confinement in dual radio-frequency driven atmospheric pressure plasmas," Applied Physics Letters, vol. 101, no. 15, pp. 154107-154104, 2012.

[130] T. Murakami, K. Niemi, T. Gans, D. O'Connell, and W. G. Graham, "Afterglow chemistry of atmospheric-pressure heliumoxygen plasmas with humid air impurity," Plasma Sources Science and Technology, vol. 23, no. 2, Article ID 025005, 2014.

[131] K. Niemi, D. O'Connell, N. de Oliveira et al., "Absolute atomic oxygen and nitrogen densities in radio-frequency driven atmospheric pressure cold plasmas: synchrotron vacuum ultra-violet high-resolution Fourier-transform absorption measurements," Applied Physics Letters, vol. 103, no. 3, Article ID 034102, 2013.

[132] J. Waskoenig and T. Gans, "Nonlinear frequency coupling in dual radio-frequency driven atmospheric pressure plasmas," Applied Physics Letters, vol. 96, no. 18, Article ID 181501, 2010.

[133] K. Niemi, S. Reuter, L. M. Graham et al., "Diagnostic based modelling of radio-frequency driven atmospheric pressure plasmas," Journal of Physics D, vol. 43, no. 12, Article ID 124006 , 2010.

[134] K. Niemi, S. Reuter, L. M. Graham, J. Waskoenig, and T. Gans, "Diagnostic based modeling for determining absolute atomic oxygen densities in atmospheric pressure helium-oxygen plasmas," Applied Physics Letters, vol. 95, no. 15, Article ID 151504, 2009.

[135] V. Schulz-von der Gathen, L. Schaper, N. Knake et al., "Spatially resolved diagnostics on a microscale atmospheric pressure plasma jet," Journal of Physics D, vol. 41, no. 19, Article ID 194004, 2008.

[136] D. Ellerweg, J. Benedikt, A. Von Keudell, N. Knake, and V. Schulz-von der Gathen, "Characterization of the effluent of a $\mathrm{He} / \mathrm{O}_{2}$ microscale atmospheric pressure plasma jet by quantitative molecular beam mass spectrometry," New Journal of Physics, vol. 12, Article ID 013021, 2010.

[137] G. E. Morfill, M. G. Kong, and J. L. Zimmermann, "Focus on plasma medicine," New Journal of Physics, vol. 11, Article ID 115011, 2009.

[138] M. Laroussi and F. Leipold, "Evaluation of the roles of reactive species, heat, and UV radiation in the inactivation of bacterial cells by air plasmas at atmospheric pressure," International Journal of Mass Spectrometry, vol. 233, no. 1-3, pp. 81-86, 2004.

[139] G. Fridman, A. D. Brooks, M. Balasubramanian et al., "Comparison of direct and indirect effects of non-thermal atmosphericpressure plasma on bacteria," Plasma Processes and Polymers, vol. 4, no. 4, pp. 370-375, 2007.

[140] R. E. J. Sladek and E. Stoffels, "Deactivation of Escherichia coli by the plasma needle," Journal of Physics D, vol. 38, no. 11, pp. 1716-1721, 2005.

[141] S. Perni, G. Shama, J. L. Hobman et al., "Probing bactericidal mechanisms induced by cold atmospheric plasmas with Escherichia coli mutants," Applied Physics Letters, vol. 90, no. 7, Article ID 073902, 2007.

[142] M. Moisan, J. Barbeau, S. Moreau, J. Pelletier, M. Tabrizian, and L. Yahia, "Low-temperature sterilization using gas plasmas: a review of the experiments and an analysis of the inactivation mechanisms," International Journal of Pharmaceutics, vol. 226, no. 1-2, pp. 1-21, 2001.

[143] Z. L. Petrović, S. Puač, N. Lazović et al., "Biomedical applications and diagnostics of atmospheric pressure plasma," Journal of Physics, vol. 356, no. 1, Article ID 012001, 2012.

[144] M. Y. Alkawareek, Q. Th. Algwari, G. Laverty et al., "Eradication of Pseudomonas aeruginosa biofilms by atmospheric pressure non-thermal plasma," PLoS ONE, vol. 7, no. 8, Article ID e44289, 2012.

[145] E. Stoffels, R. E. J. Sladek, and I. E. Kieft, "Gas plasma effects on living cells," Physica Scripta, vol. 2004, article 79, 2004.

[146] C. Jiang, M.-T. Chen, A. Gorur et al., "Nanosecond pulsed plasma dental probe," Plasma Processes and Polymers, vol. 6, no. 8, pp. 479-483, 2009.

[147] G. Isbary, G. Morfill, H. U. Schmidt et al., "A first prospective randomized controlled trial to decrease bacterial load using cold atmospheric argon plasma on chronic wounds in patients," British Journal of Dermatology, vol. 163, no. 1, pp. 78-82, 2010.

[148] G. Isbary, J. Heinlin, T. Shimizu et al., "Successful and safe use of 2 min cold atmospheric argon plasma in chronic wounds: results of a randomized controlled trial," British Journal of Dermatology, vol. 167, no. 2, pp. 404-410, 2012.

[149] G. Daeschlein, S. Scholz, R. Ahmed et al., "Cold plasma is well-tolerated and does not disturb skin barrier or reduce skin moisture," Journal der Deutschen Dermatologischen Gesellschaft, vol. 10, no. 7, pp. 509-515, 2012.

[150] M. B. Witte and A. Barbul, "Role of nitric oxide in wound repair," American Journal of Surgery, vol. 183, no. 4, pp. 406-412, 2002.

[151] A. Soneja, M. Drews, and T. Malinski, "Role of nitric oxide, nitroxidative and oxidative stress in wound healing," Pharmacological Reports, vol. 57, pp. 108-119, 2005.

[152] G. Fridman, G. Friedman, A. Gutsol, A. B. Shekhter, V. N. Vasilets, and A. Fridman, "Applied plasma medicine," Plasma Processes and Polymers, vol. 5, no. 6, pp. 503-533, 2008.

[153] G. Lloyd, G. Friedman, S. Jafri, G. Schultz, A. Fridman, and K. Harding, "Gas plasma: medical uses and developments in 
wound care," Plasma Processes and Polymers, vol. 7, no. 3-4, pp. 194-211, 2010.

[154] J. Heinlin, G. Morfill, M. Landthaler et al., "Plasma medicine: possible applications in dermatology," Journal der Deutschen Dermatologischen Gesellschaft, vol. 8, no. 12, pp. 968-976, 2010.

[155] K. R. Stalder, D. F. McMillen, and J. Woloszko, "Electrosurgical plasmas," Journal of Physics D, vol. 38, no. 11, pp. 1728-1738, 2005.

[156] J. Raiser and M. Zenker, "Argon plasma coagulation for open surgical and endoscopic applications: state of the art," Journal of Physics D, vol. 39, no. 16, Article ID 3520, 2006.

[157] J. M. Canard and B. Védrenne, "Clinical application of argon plasma coagulation in gastrointestinal endoscopy: has the time come to replace the laser?" Endoscopy, vol. 33, no. 4, pp. 353-357, 2001.

[158] B. Geavlete, R. Multescu, M. Dragutescu, M. Jecu, D. Georgescu, and P. Geavlete, "Transurethral resection (TUR) in saline plasma vaporization of the prostate vs standard TUR of the prostate: "The better choice" in benign prostatic hyperplasia?" BJU International, vol. 106, no. 11, pp. 1695-1699, 2010.

[159] L. P. Xie, J. Qin, X. Y. Zheng et al., "Transurethral vapor enucleation and resection of prostate with TURis button electrode," Zhonghua Yi Xue Za Zhi, vol. 92, no. 22, pp. 1558-1559, 2012.

[160] S. Y. Zhang, H. Hu, X. P. Zhang et al., "Efficacy and safety of bipolar plasma vaporization of the prostate with, "button-type" electrode compared with transurethral resection of prostate for benign prostatic hyperplasia," Chinese Medical Journal, vol. 125, no. 21, pp. 3811-3814, 2012.

[161] G. Fridman, A. Shereshevsky, M. M. Jost et al., "Floating electrode dielectric barrier discharge plasma in air promoting apoptotic behavior in Melanoma skin cancer cell lines," Plasma Chemistry and Plasma Processing, vol. 27, no. 2, pp. 163-176, 2007.

[162] G.-C. Kim, H. J. Lee, and C.-H. Shon, "The effects of a micro plasma on melanoma (G361) cancer cells," Journal of the Korean Physical Society, vol. 54, no. 2, pp. 628-632, 2009.

[163] S. Arndt, E. Wacker, Y. F. Li et al., "Cold atmospheric plasma, a new strategy to induce senescence in melanoma cells," Experimental Dermatology, vol. 22, no. 4, pp. 284-289, 2013.

[164] S. Iseki, K. Nakamura, M. Hayashi et al., "Selective killing of ovarian cancer cells through induction of apoptosis by nonequilibrium atmospheric pressure plasma," Applied Physics Letters, vol. 100, no. 11, Article ID 113702, 2012.

[165] C.-H. Kim, S. Kwon, J. H. Bahn et al., "Effects of atmospheric nonthermal plasma on invasion of colorectal cancer cells," Applied Physics Letters, vol. 96, no. 24, Article ID 243701, 2010.

[166] X. Zhang, M. Li, R. Zhou, K. Feng, and S. Yang, "Ablation of liver cancer cells in vitro by a plasma needle," Applied Physics Letters, vol. 93, no. 2, Article ID 021502, 2008.

[167] M. Wang, B. Holmes, X. Cheng et al., "Cold atmospheric plasma for selectively ablating metastatic breast cancer cells," PLoS ONE, vol. 8, no. 9, Article ID e73741, 2013.

[168] N. K. Kaushik, P. Attriemail, N. Kaushikemail et al., "A preliminary study of the effect of DBD plasma and osmolytes on T98G brain cancer and HEK non-malignant cells," Molecules, vol. 18, no. 5, pp. 4917-4928, 2013.

[169] D. O'Connell, L. J. Cox, W. B. Hyland et al., "Cold atmospheric pressure plasma jet interactions with plasmid DNA," Applied Physics Letters, vol. 98, no. 4, Article ID 043701, 2011.

[170] I. E. Kieft, M. Kurdi, and E. Stoffels, "Reattachment and apoptosis after plasma-needle treatment of cultured cells," IEEE
Transactions on Plasma Science, vol. 34, no. 4, pp. 1331-1336, 2006.

[171] N. Barekzi and M. Laroussi, "Dose-dependent killing of leukemia cells by low-temperature plasma," Journal of Physics D, vol. 45, no. 42, 2012.

[172] M. Vandamme, E. Robert, S. Dozias et al., "Response of human glioma U87 xenografted on mice to non thermal plasma treatment," Plasma Medicine, vol. 1, no. 1, pp. 27-43, 2011.

[173] O. Volotskova, T. S. Hawley, M. A. Stepp et al., "Targeting the cancer cell cycle by cold atmospheric plasma," Scientific Reports, vol. 2, article 636, 2012.

[174] M. Vandamme, E. Robert, S. Lerondel et al., "ROS implication in a new antitumor strategy based on non-thermal plasma," International Journal of Cancer, vol. 130, no. 9, pp. 2185-2194, 2012.

[175] G. J. Kim, W. Kim, K. T. Kim, and J. K. Lee, "DNA damage and mitochondria dysfunction in cell apoptosis induced by nonthermal air plasma," Applied Physics Letters, vol. 96, no. 2, Article ID 021502, 2010.

[176] M. Thiyagarajan, X. F. Gonzales, and H. Anderson, "Regulated cellular exposure to non-thermal plasma allows preferentially directed apoptosis in acute monocytic leukemia cells," Studies in Health Technology and Informatics, vol. 184, pp. 436-442, 2013.

[177] R. M. Walk, J. A. Snyder, P. Srinivasan et al., "Cold atmospheric plasma for the ablative treatment of neuroblastoma," Journal of Pediatric Surgery, vol. 48, no. 1, pp. 67-73, 2013.

[178] J. T. Au, T. P. Kingham, K. Jun et al., "Irreversible electroporation ablation of the liver can be detected with ultrasound B-mode and elastography," Surgery, vol. 153, no. 6, pp. 787-793, 2013.

[179] J. Fanta, P. Hora’k, J. Marvan et al., "The NanoKnife and two successful cases of intracavitary irreversible electroporation of main bronchus tumours," Rozhledy v Chirurgii, vol. 91, no. 11, pp. 625-630, 2012.

[180] G. Onik, P. Mikus, and B. Rubinsky, "Irreversible electroporation: implications for prostate ablation," Technology in Cancer Research and Treatment, vol. 6, no. 4, pp. 295-300, 2007.

[181] L. Brulle, M. Vandamme, D. Riès et al., "Effects of a non thermal plasma treatment alone or in combination with gemcitabine in a MIA PaCa2-luc orthotopic pancreatic carcinoma model," PLoS ONE, vol. 7, no. 12, Article ID e52653, 2012.

[182] D. Dobrynin, G. Fridman, G. Friedman, and A. Fridman, "Physical and biological mechanisms of direct plasma interaction with living tissue," New Journal of Physics, vol. 11, Article ID 115020, 2009.

[183] S. Kalghatgi, G. Friedman, A. Fridman, and A. M. Clyne, "Endothelial cell proliferation is enhanced by low dose nonthermal plasma through fibroblast growth factor-2 release," Annals of Biomedical Engineering, vol. 38, no. 3, pp. 748-757, 2010.

[184] D. Hirst and T. Robson, "Targeting nitric oxide for cancer therapy," Journal of Pharmacy and Pharmacology, vol. 59, no. 1, pp. 3-13, 2007.

[185] D. J. Stuehr and C. F. Nathan, "Nitric oxide: a macrophage product responsible for cytostasis and respiratory inhibition in tumor target cells," Journal of Experimental Medicine, vol. 169, no. 5, pp. 1543-1555, 1989.

[186] A. Korkmaz, S. Oter, M. Seyrek et al., "Molecular, genetic and epigenetic pathways of peroxynitrite-induced cellular toxicity," Interdisciplinary Toxicology, vol. 2, no. 4, pp. 219-228, 2009.

[187] J. Fraszczak, M. Trad, N. Janikashvili et al., "Peroxynitritedependent killing of cancer cells and presentation of released 
tumor antigens by activated dendritic cells," Journal of Immunology, vol. 184, no. 4, pp. 1876-1884, 2010.

[188] J. S. Sousa, K. Niemi, L. J. Cox, Q. T. Algwari, T. Gans, and D. O'Connell, "Cold atmospheric pressure plasma jets as sources of singlet delta oxygen for biomedical applications," Journal of Applied Physics, vol. 109, no. 12, Article ID 123302, 2011.

[189] V. Puech, G. Bauville, B. Lacour et al., "Micro-plasmas as efficient generators of singlet delta oxygen-art. no. 700527," High-Power Laser Ablation Vii, Pts 1-2, vol. 7005, article 527, 2008.

[190] A. A. Ionin, I. V. Kochetov, A. P. Napartovich, and N. N. Yuryshev, "Physics and engineering of singlet delta oxygen production in low-temperature plasma," Journal of Physics D, vol. 40, no. 2, article R01, pp. R25-R61, 2007.

[191] M. Keidar, R. Walk, A. Shashurin et al., "Cold plasma selectivity and the possibility of a paradigm shift in cancer therapy," British Journal of Cancer, vol. 105, no. 9, pp. 1295-1301, 2011.

[192] G. J. Kim, S. R. Park, G. C. Kim, and J. K. Lee, “Targeted cancer treatment using anti-EGFR and -TFR antibody-conjugated gold nanoparticles stimulated by nonthermal air plasma," Plasma Medicine, vol. 1, no. 1, pp. 45-54, 2011.

[193] M. Keidar, A. Shashurin, O. Volotskova et al., "Cold atmospheric plasma in cancer therapy," Physics of Plasmas, vol. 20, no. 5, Article ID 057101, 8 pages, 2013.

[194] H. U. Ahmed, R. G. Hindley, L. Dickinson et al., "Focal therapy for localised unifocal and multifocal prostate cancer: a prospective development study," The Lancet Oncology, vol. 13, no. 6, pp. 622-632, 2012.

[195] L. Klotz, “Active surveillance: patient selection," Current Opinion in Urology, vol. 23, no. 3, pp. 239-244, 2013.

[196] B. Tareen, G. Godoy, and S. S. Taneja, "Focal therapy: a new paradigm for the treatment of prostate cancer," Reviews in Urology, vol. 11, no. 4, pp. 203-212, 2009.

[197] K. F. Sullivan and E. D. Crawford, "Targeted focal therapy for prostate cancer: a review of the literature," Therapeutic Advances in Urology, vol. 1, no. 3, pp. 149-159, 2009. 


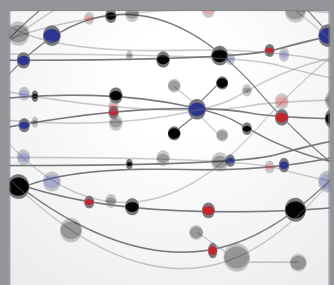

The Scientific World Journal
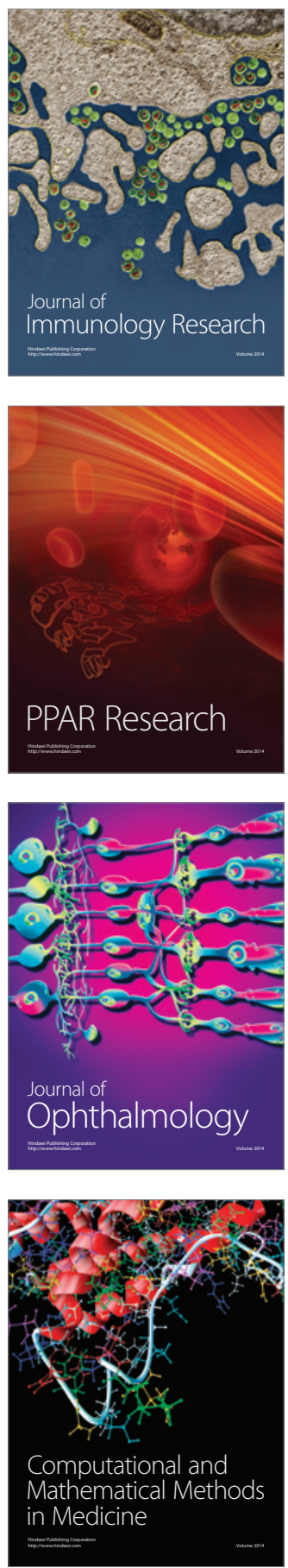

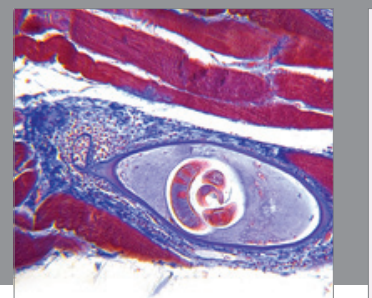

Gastroenterology

Research and Practice
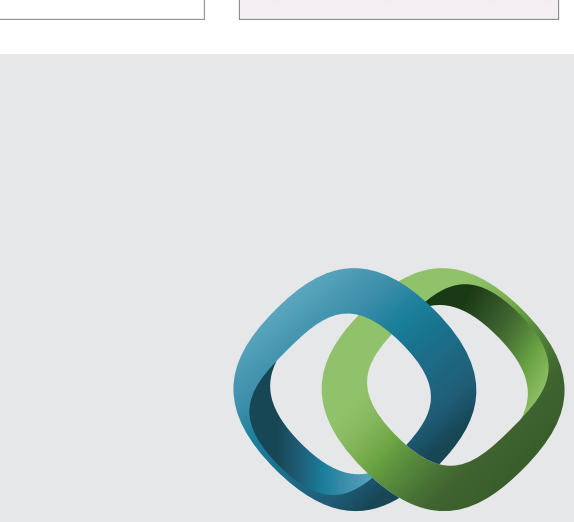

\section{Hindawi}

Submit your manuscripts at

http://www.hindawi.com
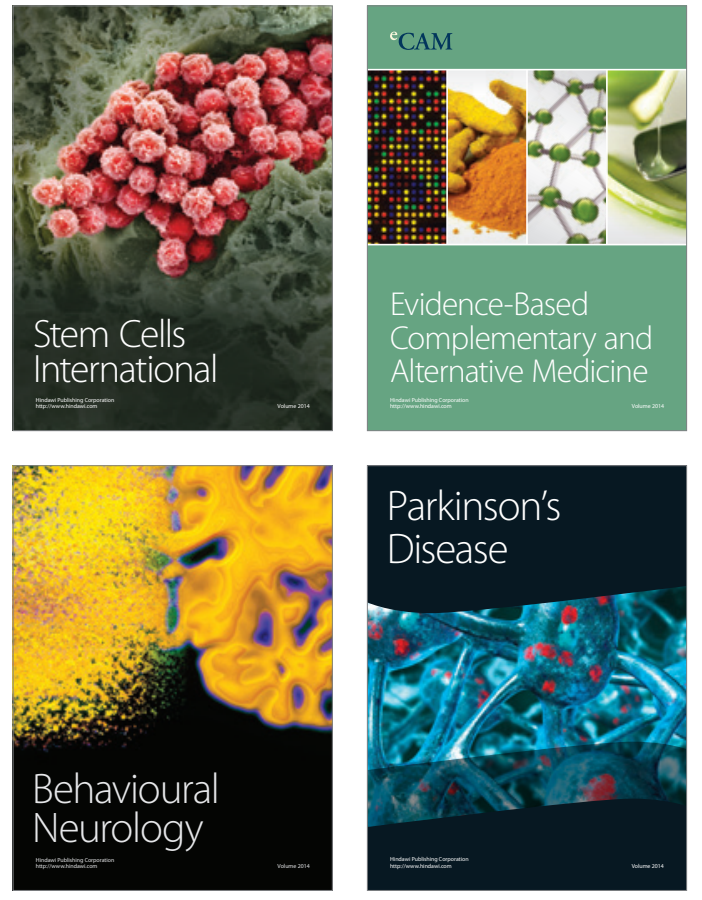
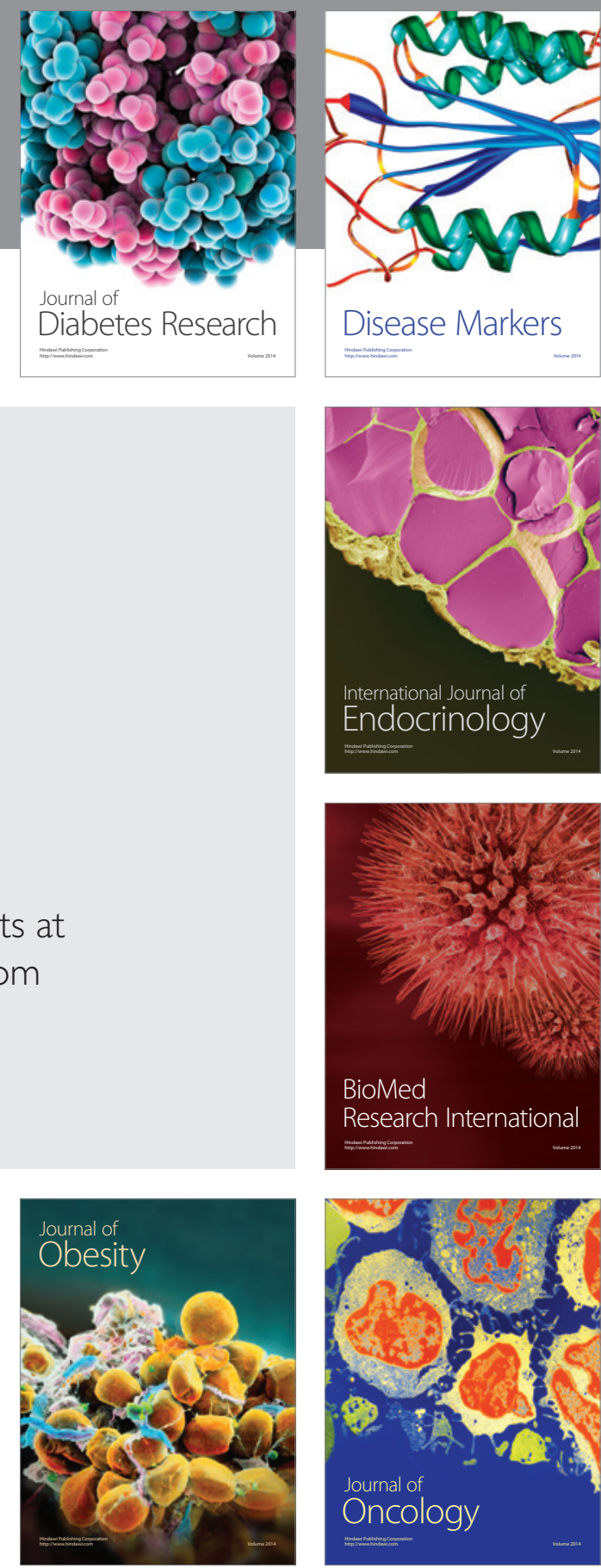

Disease Markers
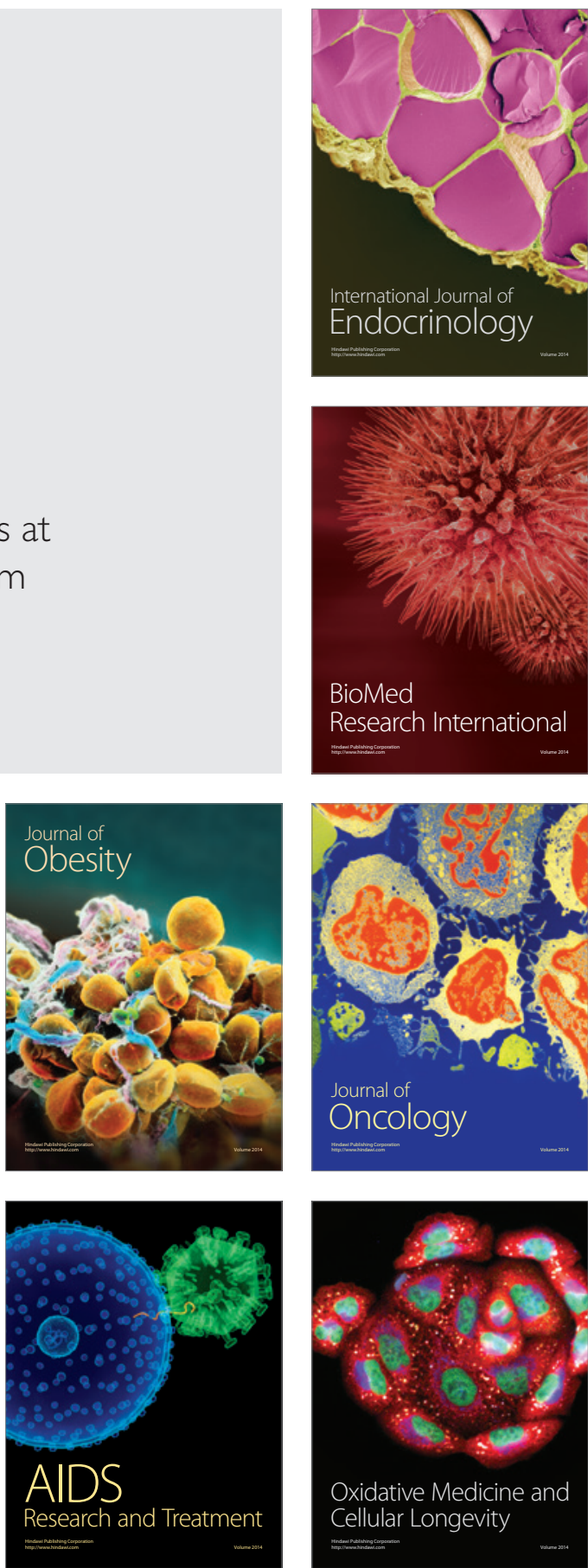